\title{
Diagnostic Approach in Acute Myeloid Leukemias in Line with WHO 2008 Classification
}

\author{
Manu Goyal and K. Gayathri \\ Lifeline Tapadia Diagnostic Services, Hyderabad \\ India
}

\section{Introduction}

The last four decades have witnessed major transformations in the approach to the diagnostic work-up and therapeutics in the field of hematology. The identification of the Philadelphia chromosome in Chronic Myelogenous Leukemia has served as a prototype for diagnosis and subsequent monitoring of response. This discovery has led to the understanding of the pathogenesis and subsequent developments in therapeutic targeting the pathways. These principles have helped evolve therapeutic strategies aimed at molecular pathways in several disorders. Acute leukemias were classified based on morphology and cytochemistry supplemented by immunophenotyping, as proposed by the French-American-British (FAB) group. Following advances and greater access to immunophenotyping techniques and simultaneous refinements in cytogenetic methods, the MIC groups proposed the classification of acute leukemias incorporating morphology, immunologic typing and cytogenetic analysis. MIC-M classification granted recognition to molecular genetic information by formally incorporating it into the classification (Bain BJ, 1998).

In 2001, the World Health Organization (WHO), in collaboration with the Society for Hematopathology and the European Association of Haematopathology, published a Classification of Tumors of the Hematopoietic and Lymphoid Tissues as part of its $3^{\text {rd }}$ edition of the series, WHO Classification of Tumors (Jaffe ES et al, 2001). This classification system was a worldwide consensus classification system for hematological malignancies. It stratified neoplasms according to the lineage. Within each category distinct entities are defined based on morphology, immunophenotype, genetic features and clinical syndromes. The classification reflected a paradigm shift from previous schemes as for the first time, genetic information was incorporated. A revised classification was published in 2008 as the 4th edition of the WHO monograph series (Swerdlow SH et al, 2008). The revision incorporates new scientific and clinical information. Refined diagnostic criteria for previously described neoplasms and newly recognized distinct entities have been defined. The new classification defines 108 new diagnostic entities in hematopathology, including 50 new or provisional leukemia entries and also recognizes provisional entities that have a definite prognostic significance (Arber DA, 2010; Betz BL \& Hess JL, 2010; Swerdlow SH et al, 2008). 


\section{WHO 2008 recommendations for work-up of AML}

WHO 2008 is one of the most scientifically devised systems to diagnose, prognosticate and also accordingly treat the haematological malignancies. The objectives are to work-up a case to obtain the information on all variables, which affect the outcome. However, for much of the world population where funding options are restricted, stringent diagnostic algorithms are a major deterrent in the management of acute leukemias. Resources are spread between diagnostic and therapeutic needs. We present here a workable and practical approach to address the need for important diagnostic parameters in AML with the focus on identifying potentially curable ones in the resource-constrained areas.

\section{Diagnostic work-up}

There is no single "gold standard" protocol for the diagnosis and classification as per the WHO 2008 system which broadly categorises AML as follows -

a. AML with recurrent genetic abnormalities

b. AML with myelodysplasia-related changes

c. Therapy related myeloid neoplasms

d. AML (not otherwise categorized)

e. Myeloid sarcoma

f. Myeloid proliferations related to Down syndrome

g. Blastic plasmacytoid dendritic cell neoplasm (BPDC)

The categories A, B, C, and F require genetic studies and/or clinical history to classify.

Morphology is always essential and sometimes it is diagnostic. Common ancillary studies relevant to bone marrow diagnosis are: cytogenetics, FISH studies, molecular studies (typically PCR or RT-PCR) for antigen receptor gene rearrangements and/or to detect specific translocations, immunophenotyping and immunohistochemistry. These tests will confirm the diagnosis of AML, subcategorize them, add to prognostication and more importantly differentiate from the related malignancies. The latter include acute leukemias of ambiguous lineage - acute undifferentiated leukemia (AUL) and mixed phenotypic acute leukemia (MPAL); non-Hodgkin lymphomas, round cell tumors and other metastases. Such information derived at the time of diagnosis is at the discretion of the treating physician and the pathologist subject to availability of expertise and affordability of the patient.

\subsection{Morphology}

The starting point for diagnosis of leukemia is morphologic examination of bone marrow or blood to document the presence of at least $20 \%$ blasts. Rarely the diagnosis is based on trephine biopsy or tissue biopsy.

\subsubsection{Peripheral blood and bone marrow aspirate}

The blasts were earlier categorized as type I and II based on criteria proposed by the FAB group (Bain BJ, 2003; Mufti GJ et al, 2008). Type I blasts lack granules and have uncondensed chromatin, a high nucleocytoplasmic $(\mathrm{N}: \mathrm{C})$ ratio and usually prominent nucleoli (Figure 1a). Type II blasts resemble type I blasts except for the presence of a few azurophilic granules and a slightly lower N:C ratio (Figure 1b). Goasguen et al defined type III blasts, which had more than 20 azurophilic granules, otherwise with typical blast 
morphology (Goasguen JE et al, 1991; Mufti GJ et al, 2008). The WHO 2001 classification lacked specific definition of blasts. However, in the WHO 2008 classification, the blasts are

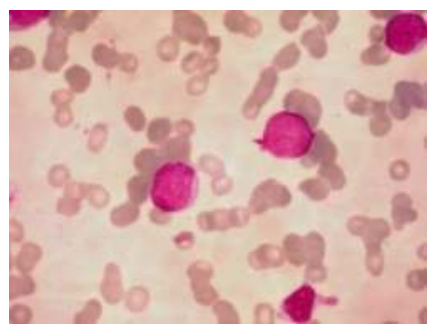

1(a)

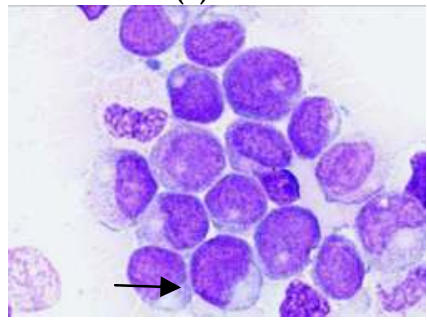

1(c)

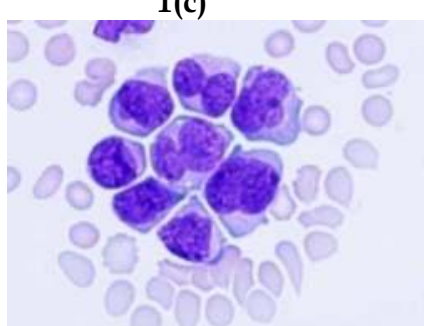

1(e)

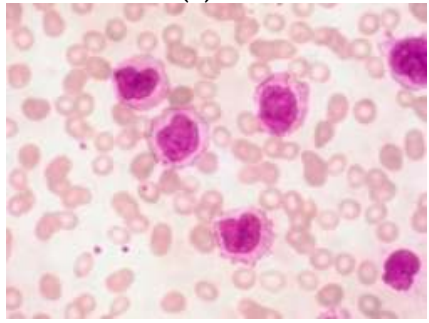

1(g)

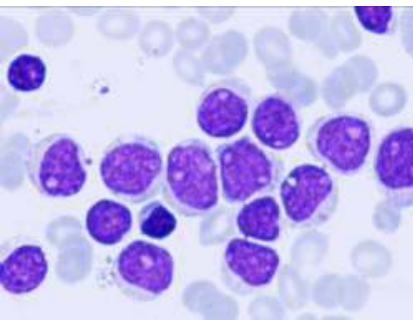

1(b)

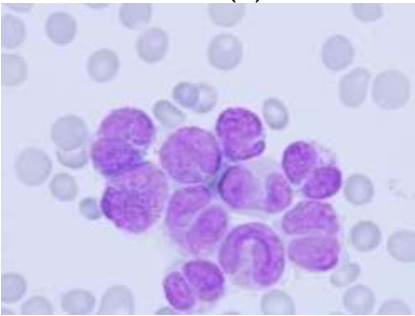

1(d)

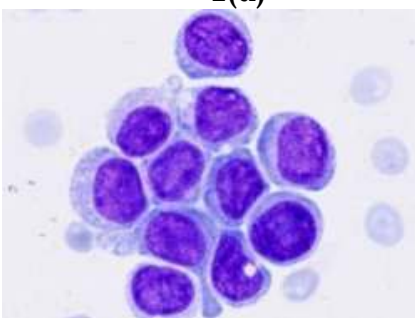

1(f)

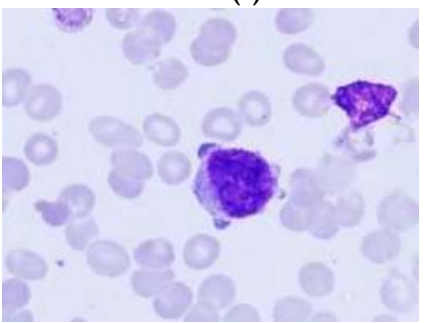

1(h)

Fig. 1. Different types of blasts in AML (1000x; Giemsa)

(a) Type 1 Blasts with scant agranular cytoplasm (b)Type 2 blasts showing moderate granular cytoplasm (c) Type 2 blasts with perinuclear hof, characteristic of $t(8 ; 21)$, a single blast shows Auer rod [arrow] (d) Abnormal promyelocytes with hypergranular cytoplasm and convoluted nucleus (e) Abnormal promyelocytes of Microgranular variant type of APL (f) Monoblasts with abundant blue-grey cytoplasm (g) Promonocytes with convoluted nuclei (h) Megakaryoblasts with characteristic cytoplasmic blebs 
defined according to the criteria proposed by the International Working Group on Morphology of Myelodysplastic Syndrome (Mufti GJ et al, 2008; Swerdlow SH et al, 2008; Vardiman JW et al, 2009).

Myeloblasts were defined as the cells with high $\mathrm{N}: \mathrm{C}$ ratio, easily visible nucleoli and usually fine nuclear chromatin, however, with a variable nuclear shape. Cytoplasmic features are variable in terms of basophilia, granules and Auer rods. Golgi zones are not detected except in cases of AML with $t(8 ; 21)$, where these are prominent and seen as perinuclear clearing or hofs (Figure 1c). The agranular blasts corresponded to FAB type I blasts and the granular blasts included both type II blasts of FAB and type III blasts of Goasguen JE et al (Mufti GJ et al, 2008; Goasguen JE et al 1991; Swerdlow SH et al, 2008). The promyelocytes of acute promyelocytic leukemia (APL) with PML-RARA are the blast equivalents and these are morphologically of two types - the classical or hypergranular and the microgranular or hypogranular types (Vardiman JW et al, 2002). The hypergranular promyelocytes are characterized by kidney-shaped or bilobed nuclei, although the shape may greatly vary (Liso V \& Bennett J, 2003; Sainty D et al, 2000). The cytoplasm is marked by densely-packed granules, sometimes may obscure nuclear margins, and variable presence of Auer rods (Figure 1d). Some cells may be characterized by bundles of Auer rods (faggot cells). The promyelocytes of microgranular variant have bilobed, multilobed, or reniform nucleus and under usual staining are devoid of granules or contain fine azurophilic granules (Figure 1e) (Golomb HM et al, 1980; Sainty D et al, 2000). There are few cases of variant RARA translocations; of these those associated with ZBTB16 fusion partner at 11q23 have a characteristic morphology. These cells have regular nuclei, many granules, usual absence of Auer rods, and an increased number of Pelgeroid neutrophils (Corey SJ et al, 1994; Melnick A \& Licht JD, 1999; Sainty D et al, 2000) . Monoblasts are large cells with abundant cytoplasm, which is light grey to deeply blue and may show pseudopod formation (Figure 1f). The nuclei are round to oval with delicate lacy chromatin and prominent nucleoli. Promonocytes are counted as monoblast equivalents (Vardiman JW et al, 2002). These cells have a delicate convoluted, folded or grooved nucleus with finely dispersed chromatin, a small indistinct or absent nucleolus, and finely granulated cytoplasm (Figure 1g). Distinction of promonocytes from abnormal monocytes is essential but very difficult on morphological basis as the diagnosis of acute monocytic or acute myelomonocytic leukemia versus chronic myelomonocytic leukemia depends on this distinction; therefore, flow cytometry and other methods are needed to improve specificity. The abnormal monocytes are characterized by more clumped chromatin, variably indented, folded nuclei and grey cytoplasm with more abundant lilac colored granules.

Megakaryoblasts are usually medium to large in size with a round, indented or irregular nucleus with finely reticular chromatin and one to three nucleoli. Cytoplasm is basophilic, agranular, and may show cytoplasmic blebs (Figure 1h) (Bennett JM, 1985). Small dysplastic megakaryocytes and micromegakaryocytes, seen in various myeloid neoplasms, are not blasts. Erythroid precursors (erythroblasts) are not counted as blasts, except in cases of pure erythroleukemia (a variant of AML-M6), where these are considered as blast equivalents. The cells are basically proerythroblasts, which are medium to large-sized, with round nuclei, fine chromatin and one or more nucleoli. The cytoplasm is deeply basophilic, agranular and frequently contains poorly demarcated vacuoles (Swerdlow SH et al, 2008). Acute leukemias with FLT3 mutations have characteristic blasts with nuclear invaginations spanning more than $25 \%$ of the nuclear diameter or a prominent "fishmouth" nucleus (Chen W et al, 2006; Kussick SJ et al, 2004; McCormick et al 2010). 


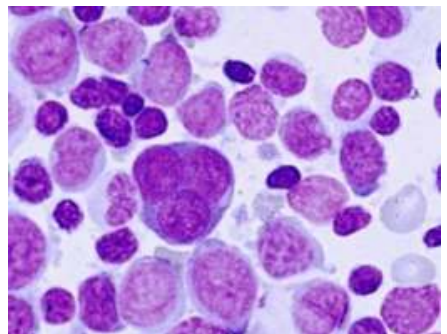

2(a)

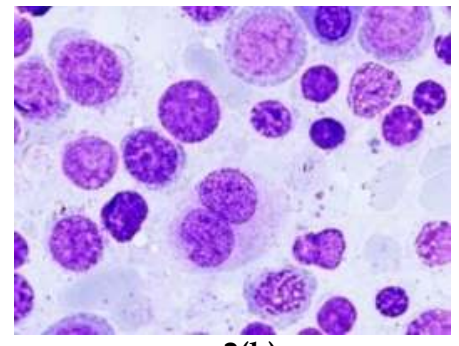

2(b)

Fig. 2. AML with myelodysplasia related changes (Giemsa stain,1000x) (a) Erythropoiesis is megaloblastoid with multinucleate erythroblasts and blasts in the background (b) Dyspoietic dwarf megakaryocytes with megaloblastoid erythropoiesis.

The blasts are expressed as the percentage of nucleated cells and the count is typically based on a 200-cell count in peripheral blood and 500-cell count in the bone marrow. If there are more than $50 \%$ erythroid precursors, the erythroid progenitors are also excluded from the blast count. This is quite important in the diagnosis of acute erythroleukemia, where the erythroid precursors are $\geq 50 \%$ of the total nucleated cells and the myeloblasts are $\geq 20 \%$ of the non-erythroid marrow nucleated cells (Swerdlow SH et al, 2008). Pure erythroid leukemia consists of precursors committed exclusively to erythroid lineage, which are $\geq 80 \%$ of marrow nucleated cells without evidence of a significant myeloblast component. In rare cases, the diagnosis of acute leukemia can be made with low marrow blast count $(<20 \%)$ when associated with recurring genetic abnormalities as $\mathrm{t}(8 ; 21)(\mathrm{q} 22 ; \mathrm{q} 22)$, inv(16)(p13.1q22), or $\mathrm{t}(16 ; 16)(\mathrm{p} 13.1 ; \mathrm{q} 22)$ or $\mathrm{t}(15 ; 17)(\mathrm{q} 22 ; \mathrm{q} 12)$ (Vardiman JW et al, 2002). These entities not only define unique disease with characteristic morphology, clinical features and biology but also have a significant prognostic implications. In AML with $\mathrm{t}(8 ; 21)$, many neoplastic cells have abundant granules that may be mistaken as promyelocytes.

Relevance of non-blast myeloid precursors: The evaluation of other precursors may give important information. The presence of immature eosinophilic granules in the promyelocyte and myelocyte stages is an important diagnostic feature of cases of AML with $\operatorname{inv}(16)(p 13.1 q 22)$, or $t(16 ; 16)(p 13.1 ; q 22)$. These granules are often larger than those normally present in immature eosinophils, purple-violet in color, and in some cases are so dense that they obscure the cell morphology. It is important to assess the degree of dysplasia in the different lineages. Dysplasia in at least $50 \%$ of the cells in 2 or more hematopoietic lineages is essential for the morphological diagnosis of AML with myelodysplasia related changes, which has adverse prognostic implications (Figures 2a and 2b) (Arber DA et al, 2003; Vardiman JW et al, 2009; Weinberg OK et al, 2009; Yanada M et al, 2005). The dysplastic features are also seen in cases of therapy-related myeloid neoplasms, AML with $\mathrm{t}(6 ; 9)(\mathrm{p} 23 ; \mathrm{q} 34)$, and AML with $\operatorname{inv}(3)(\mathrm{q} 21 \mathrm{q} 26.2)$ or $\mathrm{t}(3 ; 3)(\mathrm{q} 21 ; \mathrm{q} 26.2)$ (Swerdlow SH et al, 2008).

\section{Bone Marrow Biopsy}

It is done when the aspirate is a dry tap to evaluate for the presence of blasts (Figure 3a), especially in AML-M7 and in situations where there are significant stromal changes (Figure 3b) (Bennett JM, \& Orazi A, 2009; Lorand-Metze I et al, 1991). 


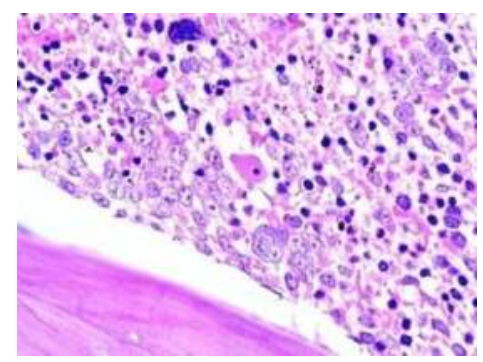

3(a)

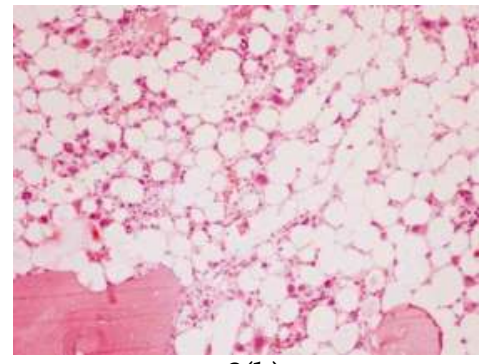

$3(\mathrm{~b})$

Fig. 3. Bone marrow biopsy in AML: (a) Paratrabecular collection of blasts with large vesicular nucleus (H\&E stain, 400x) (b) Hypoplastic AML with prominence of fat spaces, interstitial blast prominence and dyspoietic megakaryocytes in the background (H\&E stain, $100 x)$

\subsubsection{Myeloid sarcomas}

These may sometimes be preceeding or associated acute leukemias. The differentiation from lymphoblastic leukemia and round cell tumors is essential. These can involve almost any site of the body (Figure 4). These need to be differentiated from other malignancies - as lymphoblastic leukemia, lymphomas, round cell tumor, carcinomas, round cell melanomas, etc. Immunohistochemistry is done to resolve these issues. Molecular studies may be performed- FISH or PCR to further look for specific genetic abnormalities. These are a common occurence in AML with $t(8 ; 21)$. Usually these patients need allogeneic /autologous transplantation and have better survival rates as compared to other modalities as high dose chemotherapy, radiation or surgery (Pileri SA et al, 2007).

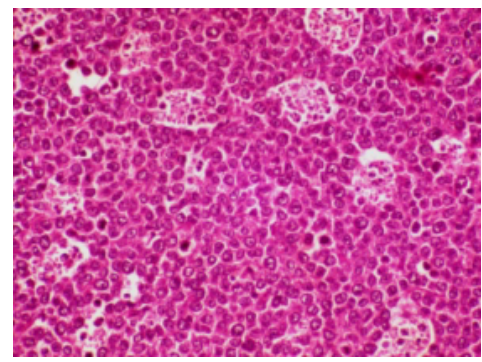

Fig. 4. Lymph node section shows sheets of large cells. These have granular cytoplasm and large convoluted nuclei. (H\&E, 400x)

\subsection{Cytochemistry}

The role of cytochemistry has become redundant in WHO 2008 with the regular use of flow cytometry for the lineage determination (Arber DA, 2010; Betz BL \& Hess JL, 2010). The stains generally used for identifying lineage type are myeloperoxidase (MPO), Sudan black $\mathrm{B}$, nonspecific esterases (NSE), chloro-acetate esterase and periodic acid- Schiff. The MPO stain is most specific indicator of myeloid differentiation (Figure 5a), however, negativity does not rule out myeloblasts. NSE is still used as one of the identifiers for monocytic differentiation. The stain that still has a definite role is the Perl's stain not only to evaluate 
iron stores, but also for identification of ringed sideroblasts (Figure 5b) (Mufti GJ et al, 2008). These stains are adjunct to morphology and useful for defining the subtypes of AMLNOS. There is a need for these stains in places where access to flow cytometry is difficult and rational decisions may still be taken through diligent practices (Scott C.S et al, 1993).

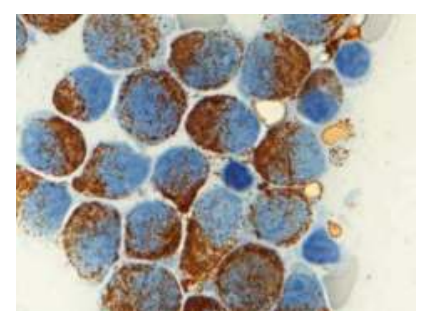

$5(a)$

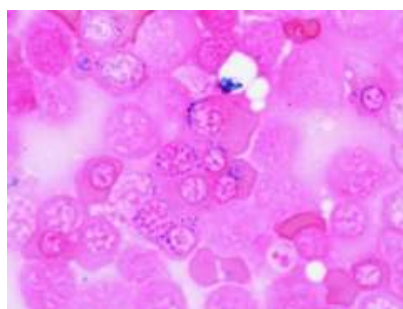

5(b)

Fig. 5. Cytochemistry in AML: (a)Myeloperoxidase stain shows golden brown granules in myeloblasts (Hematoxylin counterstain, 1000x) (b) Perl's stain demonstrates ring sideroblasts, characteristically showing Prussian blue dots around the nucleus (Eosin counterstain, 1000x)

\subsection{Flow cytometry}

Flow cytometry in hematological malignancies is based on the principle that neoplastic cells frequently show nonrandom expression of antigens in a manner that deviates from the tightly regulated patterns of antigen expression seen in normal maturation (Wood BL, 2007). Flow cytometric immunophenotyping (FCI) plays a well-established role in the diagnosis of acute leukemia, including AML, principally for blast enumeration, lineage assignment, and identification of immunophenotypic abnormalities suitable for post-therapeutic disease monitoring (Casasnovas RO et al, 1998; Orfao A et al, 2004; Peters JM \& Ansari MQ, 2011; Weir EG \& Borowitz MJ, 2001; Wood BL, 2007). It is mandatory to perform FCI to diagnose AML-M0, AML-M6, AML-M7, and acute leukemias of ambiguous lineage that include acute undifferentiated leukemia and mixed phenotypic leukemia. A three- or 4-color flow cytometer is good enough for routine diagnostic work-up, although there are some centers using 9- to 10- color flow cytometers (Kussick SJ \& Wood BL, 2003; Wood BL, 2006). Various panels have been recommended according to the type of flow cytometer, regional requirements, available resources, and personal preferences (Bene MC et al, 1995; Gujral S et al, 2008; Nguyen D et al, 2003). There is no universal consensus on the panel design. Each has its merits and limitations, undoubtedly the panels with more number of antibodies yields better results. Either bone marrow aspirate or peripheral blood containing good number of blasts can be processed for lineage typing. However, bone marrow aspirate is recommended for subtyping. In special situations, when the aspirate is a dry tap, BM core scraping suspensions can be utilized for FCI. However, because of lack of preservation of architectural features and the potential for artifactual alterations of the relative frequency of abnormal cells, the FCI data must always be correlated with histologic sections of the BM biopsy.

Recognizing a Hematopoietic Origin: The blasts express CD45, albeit have a weak expression as compared to lymphocytes, thus favoring an immature process and the differential diagnosis includes lymphoblasts, or myeloblasts. It is important to note that 
CD45 negativity does not exclude AL as some cases of B-ALL/B-LBL and all cases of AML with erythroid and megakaryocytic lineages are CD45 negative (Nguyen D et al, 2003). This feature is of vital importance.

Markers of Immaturity: CD34 is the most commonly used marker to identify a precursor stage (Table 1). CD117 demonstrates a similar expression pattern and is more sensitive than CD34 in AML (Rizzatti EG et al, 2002). Flow cytometry should not be taken as an alternative to morphology for blast enumeration as blast is a morphological definition. The percentages of CD34 positive population equivalent to blasts can vary; may be falsely decreased due to hemodilution or falsely increased due to loss of erythroid precursors (the denominator for morphologic counts includes nucleated erythroid cells). CD117 strongly favors a myeloid blast lineage because it is not seen in B-ALL and is reported only very rarely in T-ALLs $(<2 \%)$ (Paietta E et al, 2005). TdT is expressed in 20\% of AML cases, especially those with $\mathrm{t}(8 ; 21)$ (Porwit-MacDonald A et al, 1996; Wood BL, 2007). CD133 and CD38 are useful markers whenever CD34 and CD117 are non-contributory.

\begin{tabular}{|l|l|}
\hline Lineage & Markers Positive \\
\hline Precursor stage & CD34, CD117, CD133, HLA-DR, CD38, TdT \\
\hline Granulocytic markers & $\begin{array}{l}\text { CD13, CD15, CD16, CD33, CD65, cytoplasmic } \\
\text { myeloperoxidase (cMPO) }\end{array}$ \\
\hline Monocytic markers & $\begin{array}{l}\text { Nonspecific esterase (NSE), CD11c, CD14, CD64, } \\
\text { lysozyme, CD4, CD11b, CD36 }\end{array}$ \\
\hline Megakaryocytic markers & $\begin{array}{l}\text { CD41 (glycoprotein IIb/IIIa), CD61 (glycoprotein IIIa), } \\
\text { CD42 (glycoprotein 1b) }\end{array}$ \\
\hline Erythroid markers & CD235a (glycophorin A), CD71 \\
\hline B-lymphoid markers & CD19, CD10, CD22 \\
\hline T-lymphoid markers & cytoplasmic CD3, CD2, CD5, CD7 \\
\hline NK cell markers & CD16, CD56 \\
\hline
\end{tabular}

Table 1. Usual antigens associated with stage and lineages of blasts

HLA-DR in AML: HLA-DR is expressed in most AML and is characteristically negative in APL and AML-M6 and up to half of AML-M7. HLA-DR negativity once thought to be characteristically associated with APL has now been found to be present in a subset of AML with cup-shaped nuclei and FLT-3 gene internal tandem duplication (Bain BJ et al, 2002; Craig FE \& Foon KA, 2008; Kussick SJ et al, 2004; Nguyen D et al, 2003).

Myeloid lineage Antigens: Myeloblasts are well recognized for demonstrating marked immunophenotypic heterogeneity. Thus, multiple lineage-specific antibodies may be necessary to confirm the AML classification. CD13 and CD33 are the most sensitive myeloid markers. The assigning of myeloid lineage relies on identifying the expression of antigens characteristic of early myelomonocytic differentiation, including CD13, CD15, CD33, CD64, CD117, and cytoplasmic myeloperoxidase (Bain BJ et al, 2002; Chang CC et al, 2000; Cohen PL et al 1998; Craig FE \& Foon KA, 2008; Wood BL, 2007). CD64 is expressed in AML subtypes M0 to M5 in varying intensities: strong expression characterizes AML M5, whereas heterogeneous, dim, or moderate expression is seen in M0 through M4 subtypes. However, the pattern of any CD64 expression when associated with strong CD15 expression distinguishes AML-M4 or M5, from other AML subtypes (Dunphy CH \& Tang W, 2007). Promonocytes are characterized by the expression of high CD64, low CD13, intermediate 
CD15 and CD36, and high HLA-DR without significant CD34, minimal CD117, and, importantly, with low to absent CD14 (Wood BL, 2007). These are distinguished from more mature monocytes by more uniform high expression of HLA-DR, lower CD13 and CD36, higher CD15, and low to absent CD14. This demarcation is important when one objectively needs to differentiate AML-M5 from CMML. The current WHO 2008 recommendation is the expression of myeloperoxidase for assigning the cells as myeloblasts and presence of at least two of the following parameters to assign as monoblasts - NSE, CD11c, CD14, CD64, and lysozyme (Swerdlow SH et al, 2008). Erythroid lineage is identified by the expression of Glycophorin A, CD71, CD36 with CD117 in absence of CD64. Megakaryocytic lineage is characterized by the expression of CD41 and CD61 (Bain BJ et al, 2002; Craig FE \& Foon KA, 2008; Wood BL, 2007).

Lymphoid Antigens in AML: Aberrant expression of lymphoid antigens, such as CD2, CD5, CD7, CD19, and CD56, is common and generally does not indicate bilineal or mixed lineage differentiation (Auger MJ et al, 1992; Baer MR et al, 1997; Khalidi HS et al, 1998; Kita K et al,1992; Wood BL, 2007). The presence of cytoplasmic or surface CD3 is essential to designate blasts as that of T-lineage. For categorizing B-lineage blasts, when these cells express strong CD19 with one of the following- CD79a, cytoplasmic CD22 or CD10 and when the CD19 is weak, then these should express two of the above antibodies.

\subsubsection{Immunoprofiles in AMLs}

AML, Not otherwise specified: The characteristic immunoprofile of various entities (AMLM0 to AML-M7) is described above. In acute basophilic leukemia, the blasts usually express CD13 and/or CD33 with CD123, CD203c, CD11b, CD9, CD34, and HLA-DR. These are usually negative for CD117 and CD25 (Swerdlow SH et al, 2008).

AML with recurrent genetic abnormalities: There is a strong correlation of certain immunophenotypes in AML with specific cytogenetic and molecular abnormalities (Hrusak O \& Porwit-MacDonald A, 2002; Wood BL, 2007). AML with $t(8 ; 21)$ has a high incidence of aberrant expression of CD19, high CD34, CD56, and TdT (Figure 6) (Porwit-MacDonald A et al, 1996; Wood BL, 2007). t(15;17) AML demonstrates an immunophenotype typical of promyelocytes, including a variable increase in side scatter, lack of significant CD34, expression of variable CD13 and CD117, aberrantly high CD33, and aberrantly low to absent CD15 (Orfao A et al, 1999; Wood BL, 2007). AML with inv (16) or t(16;16) generally displays myelomonocytic differentiation and sometimes is associated with CD2 expression (Adriaansen $\mathrm{HJ}$ et al, 1993).

AML with myelodysplasia-related changes: The immunophenotyping results vary according to the cytogenetic abnormality. Those with abnormalities of chromosomes 5 and 7 show a high incidence of CD34, TdT and CD7 expression. CD56 and / or CD7 are seen aberrantly in cases of antecedent MDS. Most noticeable is a decrease in side scatter on mature neutrophils, the flow cytometric equivalent of morphologic hypogranularity (Wells DA et al, 2003; Wood BL, 2007). However, one has to keep in mind that aged samples also give rise to hypogranularity (Wood BL, 2007).

Myeloid leukemia associated with Down's syndrome: The blasts usually are of megakaryocytic lineage with a phenotype showing positivity for CD117, CD13, CD33, CD7, CD4 (dim), CD42, CD36, CD41, CD61, CD71 and negative for MPO, CD15, CD14 and glycophorin A (Swerdlow SH et al, 2008; Xavier AC \& Taub JW, 2009). CD34 is seen in 50\% cases only. 

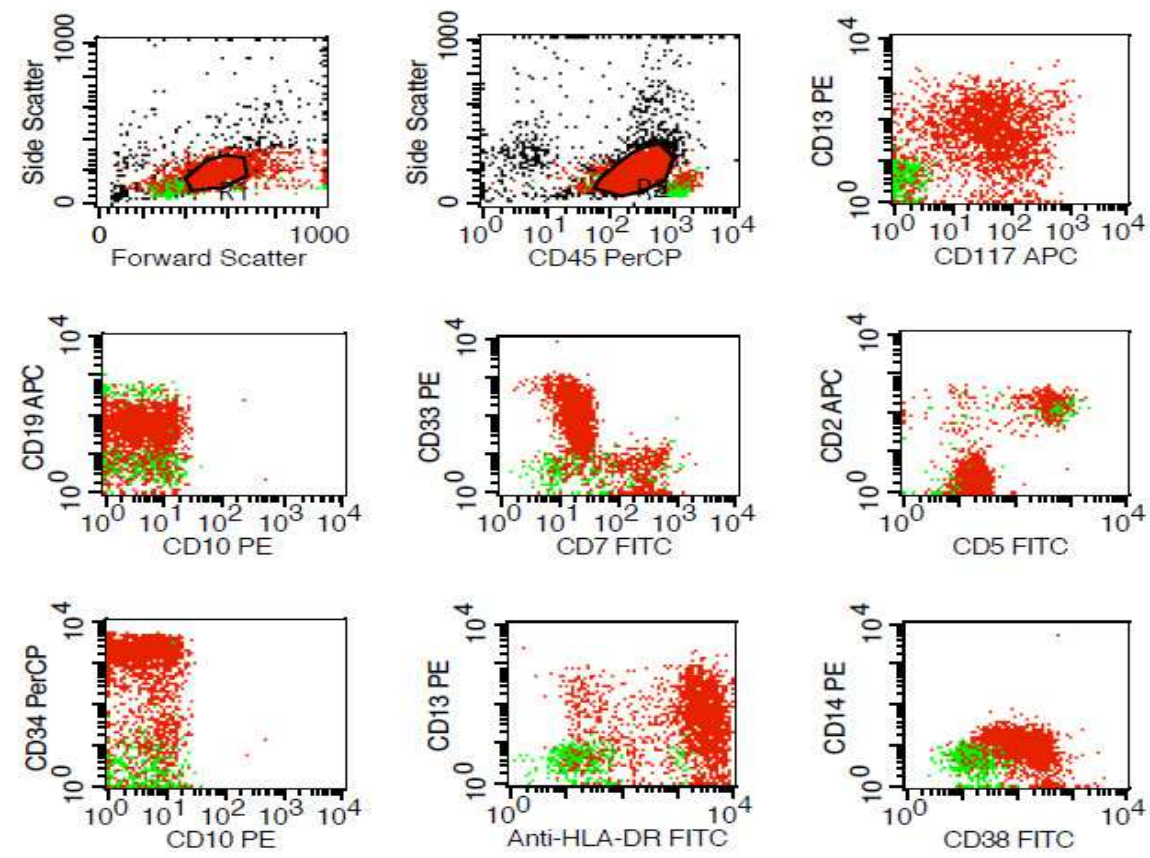

Fig. 6. Flow cytometry on the peripheral blood showed blasts (painted red) in the blast region in the CD45 / side scatter plot. These cells are CD45 dim and express CD13, CD117, CD33, CD19, CD38, CD34, and HLA-DR. These were negative for CD10, CD2, CD5, CD14 and CD7. Normal lymphocytes are painted green.

Blastic plasmacytoid dendritic cell neoplasm: Earlier known as agranular CD4+/CD56+ hematodermic neoplasm or blastic NK cell lymphoma, is characterized by the expression of CD4, CD43, CD56 and CD45RA by the blasts (Miwa H et al, 1998). These express CD123 and may sometimes express CD68, CD7, and CD33. These are negative for CD34, CD117, MPO, T-lineage and other monocytic lineage markers.

\subsubsection{Acute leukemia of ambiguous lineage}

This group includes the acute undifferentiated leukemia (AUL) and mixed phenotypic leukemias (MPAL) (Swerdlow SH et al, 2008). AUL is characterized by the absence of Tand myeloid lineage specific markers, i.e. cytoplasmic CD3 and MPO as well as cCD22, cCD79a or strong CD19. These leukemias lack erythroid, megakaryocytic and plasmacytoid dendritic cell lineage markers. These cells may express CD34, HLA-DR, and / or TdT. MPAL can show combinations of myeloid with B- or T- lineage specific antigens. Sometimes these are associated with specific chromosomal abnormalities as MPAL with $\mathrm{t}(9 ; 22)(\mathrm{q} 34 ; \mathrm{q} 11.2)$; BCR-ABL1 and MPAL with $\mathrm{t}(\mathrm{v} ; 11 \mathrm{q} 23)$; MLL rearranged, where these blasts are commonly categorized as B-lymphoblasts with a high frequency of myeloid lineage antigen expression. 


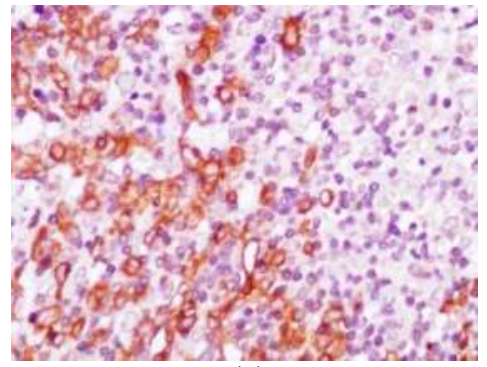

7(a)

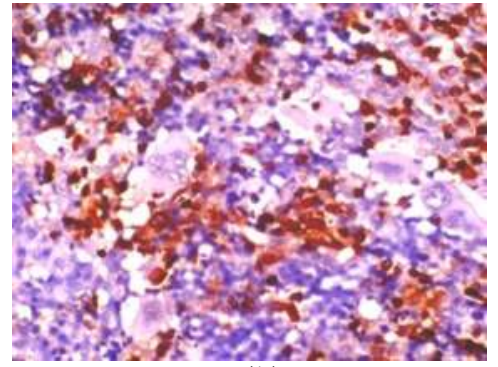

7(b)

Fig. 7. IHC on trephine biopsy section (a) Blasts show strong membranous CD34 positivity (Hematoxylin counterstain, 400x) (b) Myeloperoxidase positivity in blasts (Hematoxylin counterstain, 400x)

\subsection{Immunohistochemistry (IHC)}

Although various studies have shown that FCI is the preferred method of immunophenotyping acute leukemias, certain situations where FCI is unavailable, immunohistochemistry (IHC) is an alternate or sometimes adjunct to flow cytometry. In situations where an appropriate specimen with adequate cellularity is not available, as in a "dry tap", the diagnostic cells are low in yield, FCI is usually less informative. FCI may not be routinely requested if leukemia is not an initial diagnostic consideration, especially in extramedullary or extranodal site biopsies. Similarly, fresh cells may not be consistently submitted for consultation cases, and the technology may not be immediately accessible in community settings (Olsen RJ, 2008). The main objective of IHC is to confirm a hematologic malignancy, differentiating ALs from high grade NHLs, round cell tumors and other nonhematologic malignancies. These help categorize ALs into B-ALL, T-ALL and AML. To an extent these can also subtype AMLs (Dunphy CH, 2004). Comparison of IHC results with FCI suggests that there is significant concordance in the results for markers that can be used with both techniques, indicating that the sensitivity and specificity of both methods is comparable (Manaloor EJ, 2000).

IHC is useful in confirming the blast lineage and in categorizing the following AML groups - AML-NOS, which is subdivided based on the traditional FAB classification, myeloid sarcoma and BDPC neoplasm. AML may not be definitively classified with IHC. However, differentiation toward myeloid, monocytic, erythroid or megakaryocytic lineages can be demonstrated with appropriate staining panels. Certain staining characteristics may guide genetic testing such as fluorescence in situ hybridization studies on the paraffin-embedded tissue according to the type of blasts present (Olsen RJ, 2008). The commonly available antibodies for AML include CD45 (LCA) (marker for hemopoietic origin), CD117, CD34, TdT, HLA-DR (markers of precursor stage), MPO (specific myeloid marker), CD68, lysozyme, CD163 (markers for monocytic lineage), CD41, CD61, factor VIII (FVIII) (markers for megakaryocytic lineage), hemoglobin A1, glycophorin A (markers for erythroid lineage), and CD15 (marker for myeloid maturation). . The fact that various antibodies have variable reactivity in FC and IHC has to be kept in mind while interpreting the results. Although most studies found a better detection of CD34 by flow, some did not find any difference. CD15 and CD117 are better detected by FC analysis and MPO is better detected by IHC 
analysis (Dunphy $\mathrm{CH}$ et al, 2001). Some of the antibodies as CD13 and CD33 are not available or not standardized well by IHC.

LCA positivity recognizes a hemopoietic malignancy; however, it can be negative in AMLM6 and M7. CD34 (QBEND10) is less sensitive by IHC than by FC and is detected in only $50 \%$ of cases (Figure 7a) (Manaloor EJ, 2000; Olsen RJ, 2008). CD117 (c-Kit) is a much more sensitive marker of immaturity than CD34 and is also a marker for myeloid lineage (Rizzatti EG et al, 2002). TdT is expressed in cases of AML with $t(8 ; 21)$. Myeloperoxidase is the most specific marker for assigning myeloid lineage (Figure 7b); however, is negative in AML-M0 and blasts of monocytic, erythroid, and megakaryocytic lineages. Hemoglobin A1 and glycophorin A are positive in $90 \%$ to $100 \%$ of erythroid lineage cells, and FVIII is positive in $90 \%$ of megakaryocytic cells, but rare cases demonstrating inadequate lineage maturation (early megakaryoblasts) may be negative (Chuang SS \& Li CY, 1997; Manaloor EJ, 2000). CD41 and CD61 expression favor megakaryoblastic lineage; however, CD41 expression can be sometimes observed in other subtypes of AML. As in FCI, IHC can also demonstrate lymphoid lineage reactivity - as with CD2, CD7, CD4 and PAX-5. The expression of PAX-5 correlates highly with AML showing the t(8;21) abnormality.

The results of IHC should be evaluated carefully keeping in mind the limitations of the technique. Where there is unequivocal demonstration of immaturity, i.e. CD34 and/or CD117 expression, with MPO staining in the blasts, a diagnosis of AML can be made confidently. However, it is a challenge to interpret MPO negative AL cases. In such cases of AL, one has to first ensure that the $\mathrm{B}$ - and $\mathrm{T}$ - lymphoblastic lineages have been ruled out by a negative staining for CD79a, PAX-5, CD20, and CD3 (should detect CD3 epsilon chain and not zeta chain by a polyclonal antibody, which is non-specific) (Swerdlow SH et al, 2008). Monocytic lineage can be established using the CD68 (both KP-1 and PG-M1 epitopes) and lysozyme. Possibilities of AML-M6 or AML-M7 should be ruled out; these may be more challenging as they may be LCA negative. If the blasts express CD117 and TdT without CD79a, PAX-5, CD79a, MPO, and CD3 possibility of AML-minimally differentiated may be suggested. In the LCA negative cases, work-up towards other possibilities should be done before making a diagnosis of AL. Ancillary techniques should be appropriately used before a final conclusion. The role of IHC in the diagnosis of AL of ambiguous lineage is questionable. The possibility of AUL can be suggested when the blasts fail to express the immunophenotypic features of either lymphoid or myeloid differentiation. It is important to consider non-hemopoietic malignancies. BDPC neoplasm is a diagnosis usually based on tissue biopsy, most often a skin lesion (Petrella T et al, 1999). Morphologically suspected as leukemia cutis, the primary panel is usually inconclusive - weakly positive for LCA/CD45, variably and focally positive for CD68. The pattern may be confusing because of the absence of lineage-specific markers. The diagnosis should be suspected and a further panel should be done for a conclusive opinion. The cells are positive for CD4, CD43, CD56, and CD123 (plasmacytoid dendritic cell marker) and the expression of CD2 and CD7 is variable. This pattern may be seen in myeloid sarcoma (AML- M4 or M5). These entities are distinguished by the clinical presentation, and more importantly by CD13, and CD33 expression, which are readily available by FC. CD13 and CD33 are present in AMLs and are usually absent in BDPC (Jacob MC et al, 2003).

\subsection{Cytogenetics}

Conventional cytogenetic analysis is now an integral component of the diagnostic evaluation of a patient with suspected acute leukemia. This is done best at the time of 
diagnosis before initiating therapy. Chromosome abnormalities are detected in approximately 55\% of adult AML (Döhner H et al, 2010; Grimwade D et al, 1998). There are seven recurrent balanced translocations and inversions, and their variants recognized in the WHO category - AML with recurrent genetic abnormalities. Several cytogenetic abnormalities are considered sufficient to establish the WHO diagnosis of AML with myelodysplasia-related features, when $20 \%$ or more blood or marrow blasts are present. A minimum of 20 metaphase cells analyzed from bone marrow is considered mandatory to establish the diagnosis of a normal karyotype, and also to define an abnormal karyotype. Abnormal karyotypes may be diagnosed from blood specimens, or the biopsy core scrapings, when the marrow aspirate is scanty or insufficient. Leukemic blasts carrying AML-associated chromosome aberrations can constitute only a fraction of cells dividing in vitro. Moreover, a blood specimen can sometimes be cytogenetically normal when the marrow is abnormal. In the CALGB database, this was found in approximately $5 \%$ of AML patients whose marrow and blood specimens were studied simultaneously (Grimwade D et al, 1998; Mrózek K et al, 2001, 2007).

Acquired genetic alterations, both those detectable microscopically as structural and numerical chromosome aberrations, and those detected as submicroscopic gene mutations and changes in gene expression, are commonly seen in AML. At present, cytogenetic aberrations detected at the time of AML diagnosis constitute the most common basis for predicting clinical outcome (Byrd JC et al, 2002; Mrózek K \&Bloomfield CD, 2006; Slovak M $\mathrm{L}$ et al, 2000). Acquired clonal chromosome abnormalities are defined as a structural aberration or a trisomy observed in at least 2 and monosomy found in at least 3 metaphase cells. These are detected in the pretreatment marrow of $50 \%$ to $60 \%$ of adults with de novo AML. In $10 \%$ to $20 \%$ of patients, the abnormal karyotype is complex, defined as the presence of more than 3 abnormalities in karyotypes not including the abnormalities seen in the recurrent genetic abnormalities group, i.e. $t(8 ; 21)$, $\operatorname{inv}(16), t(16 ; 16), t(15 ; 17)$ or $t(9 ; 11)$ (Swerdlow SH et al, 2008). In around $40 \%$ to $50 \%$ of patients no cytogenetic abnormality can be detected using standard banding methods (Byrd JC et al, 2002; Farag SS et al, 2006; Grimwade D et al, 1998; Mrózek K et al, 2001, 2007; Slovak M L et al, 2000). The role of cytogenetics is of paramount importance in the diagnosis of AML with recurrent genetic abnormalities - those associated with balanced translocations and inversions, and AML with myelodysplasia-related changes.

\subsubsection{AML with balanced translocations/ inversions}

This group is composed of ALs with detection of balanced translocations between chromosomes and are usually associated with a specific prognosis. All large cytogenetic studies of AML have shown that patients with $t(15 ; 17)(\mathrm{q} 22 ; \mathrm{q} 12-21)$ have an excellent outcome and those with $\mathrm{t}(8 ; 21)(\mathrm{q} 22 ; \mathrm{q} 22)$ or inv(16)(p13q22)/ $\mathrm{t}(16 ; 16)(\mathrm{p} 13 ; \mathrm{q} 22)$ a relatively favorable prognosis. Those with inv(3)(q21q26)/ $t(3 ; 3)(q 21 ; q 26),-7$ and a complex karyotype have an unfavourable outcome (Mrózek K \&Bloomfield CD, 2006) .

\subsubsection{Core-Binding Factor (CBF) AML}

CBF-AML is a relatively frequent subtype of adult de novo AML, with $\mathrm{t}(8 ; 21)$ being detected in $7 \%$ and $\operatorname{inv}(16) / t(16 ; 16)$ in $8 \%$ of patients (Byrd JC et al, 2002; Marcucci G et al, 2005; Mrózek K \& Bloomfield CD, 2006). As in APL both these leukemias have a characteristic morphology based on which these cytogenetic abnormalities are predicted and specifically 
looked for. Both $t(8 ; 21)$ and $\operatorname{inv}(16)$ are related at the molecular level as they disrupt the $a$ and $\beta$ subunits of $\mathrm{CBF}$, respectively.

AML with t(8;21)(q22;q22); RUNX1-RUNX1T1: This abnormality detected in 20\% adult and $40 \%$ children de novo AML cases is associated usually with FAB AML-M2, rarely with other subtypes (Figure 8). Over $70 \%$ are associated with secondary chromosome aberrations - as loss of a sex chromosome ( $-Y$ in men and $-X$ in women) and $\operatorname{del}(9 q)$ with loss of $9 q 22$ being the most frequent. Despite good prognosis relapse is a major problem, especially in first 2 years of remission (Marcucci G et al, 2005; Mrózek K \& Bloomfield CD, 2006; Schlenk RF et al, 2004).

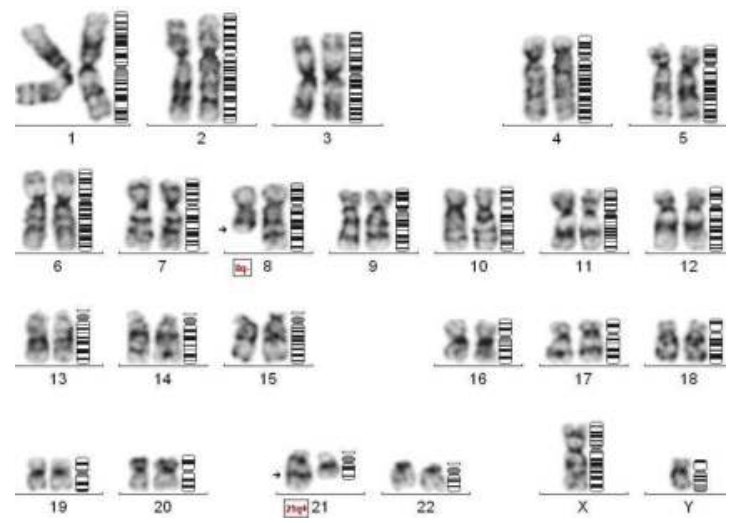

Fig. 8. Karyotype showing balanced translocation of 46,XY, t(8;21)(q22;q22)

AML with inv(16)(p13.1q22) / t(16;16) (p13.1q22); CBFB-MYH11: These are associated with characteristic FAB M4Eo morphology, higher WBCs, percentages of PB and BM blasts, more often showing extramedullary involvement, lymphadenopathy, splenomegaly, gingival hypertrophy and skin/mucosa involvement and characteristic cytogenetic features. Approximately two thirds of patients with inv(16)/t(16;16) have this rearrangement as a sole chromosome abnormality. Most frequent secondary chromosome aberrations in $\operatorname{inv}(16) / t(16 ; 16)$-positive patients are $+22,+8, \operatorname{del}(7 q)$ and +21 . These studies identified additional cytogenetic prognostic factors differentiating the two cytogenetic subsets of $\mathrm{CBF}$ AML. Among patients with inv(16)/t(16;16), those who harbored +22 as a secondary abnormality were found to have a significantly lower cumulative incidence of relapse compared with patients with $\operatorname{inv}(16) / t(16 ; 16)$ as a sole abnormality in the CALGB study and longer relapse free survival than patients without +22 in the German Acute Myeloid Leukemia Intergroup study(Marcucci G et al, 2005; Mrózek K \& Bloomfield CD, 2006; Schlenk RF et al, 2004).

\subsubsection{AML associated with RARA translocation including variant translocations}

APL constitutes 5-8\% of AML (Swerdlow SH et al, 2008). In 1977 Rowley and colleagues identified the $\mathrm{t}(15 ; 17)$ balanced reciprocal chromosomal translocation as the karyotypic hallmark of the disease (Rowley J et al, 1997 as cited in Sirulnik A et al, 2003). In the early 1990s it was discovered that in classical APL this reciprocal translocation involves a fusion between the RARA gene on chromosome 17 and a previously unknown locus named promyelocytic leukemia (PML) on chromosome 15 (Kakizuka A et al, 1991 as cited in Sirulnik A et al, 2003). Other additional chromosomal abnormalities can be found in 30 to 
$40 \%$ of patients with APL in addition to $t(15 ; 17)$. The most common of these are trisomy 8 and isochromosome 17. Additional chromosomal abnormalities do not have a negative effect on the overall prognosis (Johannson B et al, 1994; Schoch C et al. 1996; Slack JL, 1997). However, there have been cases morphologically reported as APL without a detectable $t(15 ; 17)$ on a conventional karyotype. Some of these have a cryptic PML/RARA translocation, i.e. these are submicroscopic and not detected by conventional method and require ancillary techniques as the FISH or PCR for a confirmation. Others have translocations not involving the $\mathrm{t}(15 ; 17)$ (Goyal M et al, 2010; Grimwade DF et al, 1997).

AML with Variant RARA translocations: The current WHO categorizes morphologically diagnosed cases of APL into those associated with $t(15 ; 17)(q 22 ; q 21) /$ PML-RARA rearrangement, and those lacking PML/RARA rearrangements based on the cytogenetic and molecular studies (Swerdlow SH et al, 2008). The latter group is separately categorized as variant RARA translocations due to refractory / variable response to ATRA. Instead of PML the partner genes in this group could be ZBTB16/ PLZF at 11q23, NUMA1 at 11q13, NPM1 at 5q35 and STAT5B at17q11.2.

\subsubsection{AML with $\mathrm{t}(9 ; 11)(\mathrm{p} 22 ; \mathrm{q} 23)$; MLLT3-MLL and variant MLL translocations in AL}

The MLL gene on chromosome 11 band q23 is frequently involved in chromosome translocations in acute lymphoblastic leukemia and acute myeloid leukemia. The MLL gene located at 11q23 has been described as a 'promiscuous' gene due its involvement with a large number of genetic partners (Moorman AV et al, 1998). More than 80 different partner chromosome regions have been described till date. The translocation results in the formation of a fusion gene on the derivative 11 chromosome consisting of the $5^{\prime}$ part of the MLL gene and the 3' part of another gene. MLL gene rearrangements generally correlate with a poor prognosis; however AML with $\mathrm{t}(9 ; 11)(\mathrm{p} 22 ; \mathrm{q} 23)$ is associated with intermediate prognosis. Therefore, the presence of $11 \mathrm{q} 23$ aberration has direct implications for treatment stratification, making early and rapid detection of utmost importance (van der Burg et al, 1999). AML with $t(9 ; 11)$ are associated with acute monocytic and myelomonocytic leukemias (Baer MR et al, 1998; Sorensen PHB et al, 1994; Swansbury GJ et al, 1998). This entity involves MLLT3 (AF9), which is the most common MLL translocation in AML. Secondary chromosomal abnormalities as +8 are commonly seen, however, these do not affect the prognosis.

AML with variant MLL translocations: Various other partner chromosomes are known to be associated with the MLL gene (Moorman AV et al, 1998). 19p13.1 is involved almost only with AML, others can be seen both in ALL and AML, and all have been categorized in variant MLL translocations in acute leukemia. The WHO 2001 encompassed all MLL related translocations into the category of AML with 11q abnormalities. However, the WHO 2008 now separates AML with $t(9 ; 11)$ from other MLL related translocations, which are placed in the category variant MLL translocations in acute leukemia. It is imperative to mention the specific abnormality associated with MLL to place in the latter category. Cases of AML with specific MLL translocations as $\mathrm{t}(11 ; 16)(\mathrm{q} 23 ; \mathrm{p} 13.3)$ and $\mathrm{t}(2 ; 11)(\mathrm{p} 21 ; \mathrm{q} 23)$ if not associated with cytotoxic chemotherapy should be considered as AML with myelodysplasia-related changes and not variant translocation of 11q23 (Swerdlow SH et al, 2008).

\subsubsection{AML with t(6;9)(p23;q34); DEK-NUP214}

Morphologically these are AML with or without monocytic features, usually associated with basophilia and multilineage dysplasia. The $t(6 ; 9)(p 23 ; q 34)$ results in fusion of DEK on 
chromosome 6 with NUP214 on chromosome 9. Usually it is an isolated abnormality. Very occasional reports of complex karyotype are known (Chi Y et al, 2008; Slovak ML et al, 2006). These are frequently associated with FLT3-ITD mutations and a poor prognosis.

\subsubsection{AML with inv(3)(q21q26.2) or $t(3 ; 3)(q 21 q 26.2)$; RPN1-EVI1}

These are morphologically AML with multilineage dysplasia and characterized by the translocation involving EVI1 or MDS-1EVI1 located at 3q26.2 and RPN1 at 3q21 respectively. Other abnormalities involving the 3q26.2, seen in therapy related AML are not included in this category. This group is frequently associated with secondary karyotypic abnormalities - monosomy 7, 5q deletions, and complex karyotypes. AML with $\operatorname{inv}(3)(\mathrm{q} 21 \mathrm{q} 26.2)$ or $\mathrm{t}(3 ; 3)(\mathrm{q} 21 \mathrm{q} 26.2)$ is an aggressive disease with a short survival (Lugthart $\mathrm{S}$ et al, 2008).

\begin{tabular}{|c|c|c|}
\hline \multirow[t]{2}{*}{$\begin{array}{l}\text { Karyotypic } \\
\text { abnormalities }\end{array}$} & $\begin{array}{l}\text { AML with myelodysplasia } \\
\text { related changes }\end{array}$ & $\begin{array}{l}\text { Therapy related AML } \\
\text { (t-AML) }\end{array}$ \\
\hline & Complex karyotype & Complex karyotype \\
\hline $\begin{array}{l}\text { Unbalanced } \\
\text { abnormalities }\end{array}$ & $\begin{array}{l}-7 / \operatorname{del}(7 q) ;-5 / \operatorname{del}(5 q) ; i(17 q) / \\
t(17 p) ;-13 / \operatorname{del}(13 q) ; \operatorname{del}(11 q) ; \\
\operatorname{del}(12 p) / t(12 p) ; \operatorname{del}(9 q) ; \operatorname{idic} \\
(X)(q 13)\end{array}$ & $\begin{array}{l}-7 / \operatorname{del}(7 q) ;-5 / \operatorname{del}(5 q) ; \operatorname{del}(13 q) ; \\
\text { del }(20 q) ; \operatorname{del}(11 q) ; \operatorname{del}(3 p) ; \\
-17 ;-18 ;-21 ;+8\end{array}$ \\
\hline $\begin{array}{l}\text { Balanced } \\
\text { abnormalities }\end{array}$ & $\begin{array}{l}\text { t(11;16)(q23:p13.3); } \\
\text { t(3;21)(q26.2;q22.1); } \\
\text { t(1;3)(p36.3;q21.1); } \\
\text { t(2;11)(p21;q23); t(5;12)(q33;p12); } \\
\text { t(5;7)(q33;q11.2); t(5;17)(q33;p13); } \\
\text { t(5:10)(q33;q21); } \\
\text { t(3;5)(q25;q34) }\end{array}$ & 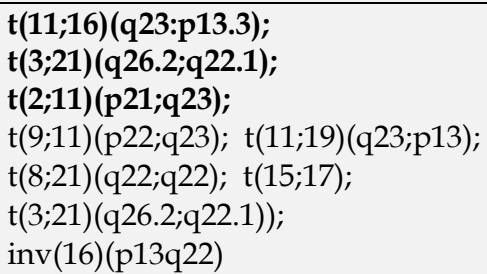 \\
\hline
\end{tabular}

Table 2. Types of cytogenetic abnormalities defining AML with myelodysplasia related changes and Therapy related AML (t-AML)

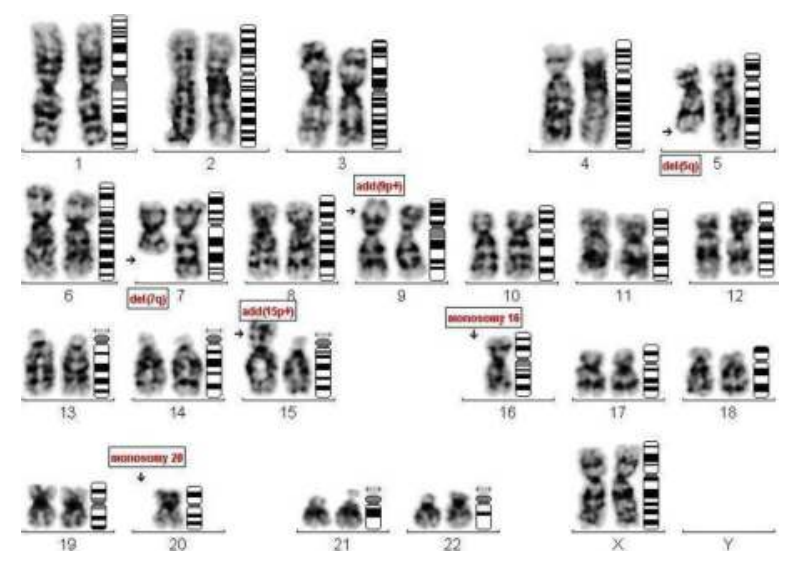

Fig. 9. Case of a t-AML, post treatment for carcinoma breast showing a complex karyotype: 44,XX,del(5q),del(7q),der(9)add(9p),der(15)add(15p),-16,-20 


\subsubsection{AML with t(1;22)(p13;q13); RBM15-MKL1}

These are morphologically acute megakaryoblastic leukemia associated with a very poor prognosis. Usually $\mathrm{t}(1 ; 22)(\mathrm{p} 13 ; \mathrm{q} 13)$ is the sole abnormality. However, cytogenetics may not always be successful to depict this abnormality due to poor bone marrow aspirate yield and one may need to resort to molecular analysis as well. When a morphological diagnosis of AML-M7 is suspected, this chromosomal/ molecular abnormality should be looked for (Swerdlow SH et al, 2008).

\subsubsection{AML with myelodysplasia related changes and therapy related AML}

The chromosomal abnormalities are similar to those found in MDS and often involve gain or loss of major segments of certain chromosomes with complex chromosomal abnormalities. Various balanced and unbalanced abnormalities are known to occur (Table 2). Some abnormalities as $\mathrm{t}(11 ; 16)(\mathrm{q} 23 ; \mathrm{p} 13.3)$ and $\mathrm{t}(3 ; 21)(\mathrm{q} 26.2 ; \mathrm{q} 22.1)$ seen in AML with myelodysplasia-related changes, also occur commonly in t-AML and clinical details should be evaluated to differentiate between the two (Secker-Walker LM et al, 1998). Trisomy 8, del $20 \mathrm{q}$ and loss of $\mathrm{Y}$ are common in MDS, however, are not considered disease-specific. Hence, their isolated presence is not sufficient to consider a case as AML with myelodysplasiarelated changes. Cases of AML with myelodysplastic changes in bone marrow may show $\mathrm{t}(6 ; 9)(\mathrm{p} 23 ; \mathrm{q} 34)$, inv(3)(q21q26.2) or $\mathrm{t}(3 ; 3)(\mathrm{q} 21 \mathrm{q} 26.2)$ on a karyotype and should be categorized as such and not in AML with myelodysplasia-related changes. In t-AML unbalanced chromosomal aberrations are seen in 70\% cases (Figure 9). These are associated with longer latent period, myelodysplastic changes and alkylating agent and/ or radiation therapy. Balanced translocations seen in $20-30 \%$ are associated with shorter latency, absence of myelodysplasia and prior therapy with topoisomerase inhibitors. The prognosis for $\mathrm{t}$ AML is dependent on the karyotype - is generally poor, except in cases associated with balanced translocations as $\mathrm{t}(15 ; 17)$ and $\operatorname{inv}(16)(\mathrm{p} 13 \mathrm{q} 22)$, which is also poorer as compared to de novo cases (Swerdlow SH et al, 2008).

\subsubsection{AML- not otherwise specified}

There are no specific chromosomal abnormalities associated with different subtypes. However, higher frequency of few abnormalities is seen in certain subtypes. Cuneo A et al, 1995 compared cases of AML-M0 and AML-M1 and showed that abnormal karyotypes, complex karyotypes, unbalanced chromosome changes $(-5 / 5 q-$ and $/$ or $-7 / 7 q-$ and +13$)$ were more frequent in AML-M0 than in AML-M1. However, many cases were regrouped in the AML with myelodysplasia-related changes. Trisomy 8 may be seen in acute myelomonocytic leukemia and $\mathrm{t}(8 ; 16)(\mathrm{p} 11.2 ; \mathrm{p} 13.3)$ may be seen in acute monocytic or myelomonocytic leukemia. Cases of AML-M7 associated with mediastinal germ cell tumors have shown several cytogenetic abnormalities of which $i(12 p)$ is the most characteristic. There are no specific abnormalities documented in other subtypes.

\subsubsection{Down's syndrome related AML}

In addition to trisomy 21 , trisomy 8 is a common cytogenetic abnormality seen in DSAML (13-44\%). More importantly the focus should be on detecting GATA1 mutations, which are commonly seen in children below 5 years (Swerdlow SH et al, 2008; Xavier AC \& Taub JW, 2009). 


\subsubsection{Blastic Plasmacytoid Dendritic Cell neoplasm}

Chromosomal abnormalities are found in two-thirds of BPDC patients, although a specific karyotype is lacking. Complex karyotypes are common and six major recurrent chromosomal abnormalities are found: $5 q 21$ or $5 q 34,12 p 13,13 q 13-21,6 q 23-q$ ter, $15 q$ and -9 .

\subsubsection{Cytogenetically normal AML (CN-AML)}

The proportion of adults with de novo CN-AML has varied between $40 \%$ and $49 \%$ in the largest cytogenetic studies (Byrd JC et al, 2002; Grimwade D et al, 2001; Mrózek K et al, 2007; Slovak ML et al, 2000). A patient is defined karyotypically normal when full analysis of at least 20 metaphase cells originating from a marrow sample cultured in vitro for 24 to 48 hours is performed (Mrózek K et al, 2007). There are patients who, despite having a normal karyotype on standard cytogenetic investigation, carry 1 of the fusion genes identical to those generated by recurrent translocations (eg, PML-RARA/t(15;17), RUNX1-RUNX1T1 (AML1-ETO)/ $\mathrm{t}(8 ; 21)$ ) or inversions (CBFB-MYH11/1nv(16)) and categorized in AML with recurrent genetic abnormalities. In most instances, these fusion genes are created by cryptic insertions of very small chromosome segments that do not alter the chromosome morphology (Grimwade D et al, 2000; Mrózek K et al, 2007; Rowe D et al, 2000). Both RT-PCR and FISH can be used to detect the presence of the aforementioned hidden rearrangements. Such testing is definitely warranted in CN-AML patients with FAB M2, M3, M3v, and M4Eo marrow morphology but is otherwise not routinely recommended outside of a clinical trial (Mrózek K et al, 2007; National Comprehensive Cancer Network (NCCN), 2006).

\subsubsection{Prognosis associated with chromosomal abnormalities}

The risk stratification with regards to cytogenetics is based on studies performed on patients below 60 years of age (Byrd JC et al, 2002; Grimwade D et al, 1998; Mrózek K \& Bloomfield CD, 2006; Slovak ML et al, 2000). The favourable risk group have only balanced translocations - include $\mathrm{t}(15 ; 17)(\mathrm{q} 22 ; \mathrm{q} 12-21), \mathrm{t}(8 ; 21)(\mathrm{q} 22 ; \mathrm{q} 22)$ and with inv(16)(p13.1q22) / $\mathrm{t}(16 ; 16)$ (p13.1q22) (Table 3). The CN-AML is included in the intermediate-risk group. The unfavourable risk group includes complex karyotype, various balanced translocations, unbalanced translocations and numerical abnormalities. An MRC study found the outcome

\begin{tabular}{|c|c|c|c|}
\hline \multirow{2}{*}{$\begin{array}{l}\text { Karyotypic } \\
\text { abnormality }\end{array}$} & Favourable & Intermediate & Poor \\
\hline & & CN-AML & Complex karyotype \\
\hline $\begin{array}{l}\text { Balanced } \\
\text { Structural } \\
\text { Rearrangements }\end{array}$ & 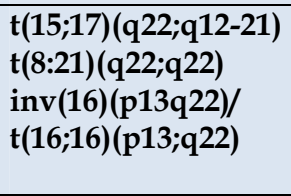 & $t(9 ; 11)(p 22 ; q 23)$ & $\begin{array}{l}\text { inv(3)(q21q26)/ } \\
\mathrm{t}(3 ; 3)(\mathrm{q} 21 ; \mathrm{q} 26) \\
\mathrm{t}(6 ; 9)(\mathrm{p} 23 ; \mathrm{q} 34) \\
\mathrm{t}(6 ; 11)(\mathrm{q} 27 ; \mathrm{q} 23) \\
\mathbf{t}(11 ; 19)(\mathrm{q} 23 ; \mathrm{p} 13.1)\end{array}$ \\
\hline $\begin{array}{l}\text { Unbalanced } \\
\text { Structural } \\
\text { Rearrangements }\end{array}$ & None & $\begin{array}{l}\operatorname{del}(7 q) \\
\operatorname{del}(9 q) \\
\operatorname{del}(11 q) \\
\operatorname{del}(20 q)\end{array}$ & $\operatorname{Del}(5 q)$ \\
\hline $\begin{array}{l}\text { Numerical } \\
\text { aberrations: }\end{array}$ & None & $\begin{array}{l}-Y ;+8 ;+11 ;+13 ; \\
+21\end{array}$ & $\begin{array}{l}-5 \\
-7\end{array}$ \\
\hline
\end{tabular}

Table 3. Known cytogenetic abnormalities with associated favourable, intermediate and unfavourable prognosis. 
of patients above 60 years with fewer than 5 abnormalities, regardless of the presence of abnormalities involving chromosomes 5,7 and $3 q$, to be comparable to the intermediate-risk category. They included only those patients with a complex karyotype with 5 or more aberrations in the adverse risk category (Grimwade D et al, 2001). A CALGB study confirmed that older AML patients with a complex karyotype with 5 or more aberrations have particularly poor disease free survival (DFS) and overall survival (OS), with no patient surviving 5 years after diagnosis (Farag SS et al, 2006).

\subsection{Fluorescent-In-Situ Hybridisation (FISH)}

FISH is an improvisation of cytogenetic technique used to detect and localize the presence or absence of specific DNA sequences on chromosomes. Karyotype analysis has an advantage that the entire genome can be analyzed however, is applicable to actively dividing cells, and the resolution is limited to chromosomal rearrangements that are $>3 \mathrm{Mb}$ in size. In addition technical aspects of sample collection, storage, transport, and culture may lead to suboptimal results. Poorly spread or contracted metaphases, low mitotic index and highly complex cytogenetic abnormalities may also lead to faulty results. This technique is labourintensive and time-consuming. FISH is capable of detecting aberrations of sizes between $10 \mathrm{~kb}$ to $5 \mathrm{Mb}$. These are accurate, rapid, however, targeted analysis of the genomes. FISH provides increased resolution, thus elucidating submicroscopic deletions, cryptic or subtle duplications and translocations, complex rearrangements, involving many chromosomes and marker chromosomes. Interphase FISH has advantages of screening more number of cells, and also that both proliferating and not proliferating cells can be analyzed. The test can be performed on fixed bone marrow suspensions, paraffin-embedded tissue sections, bone marrow or blood smears, and touch preparations of cells from tissues. The test can be reliably used for routine diagnostic screening and whenever the patient's material is not sufficient or suitable for cytogenetic/RT-PCR analysis.

Role of FISH in AML: The main applications in AML are detection of recurrent cytogenetic abnormalities, whenever the cytogenetic analysis fails or in a CN-AML case, where morphology is suggestive of AML with recurring cytogenetic abnormalities. Dual color dual- fusion probes specific for the abnormality are used when a reciprocal translocations are suspected, e.g. $\mathrm{t}(8 ; 21), \mathrm{t}(15 ; 17)$, etc (Figure 10). The presence of a translocation is

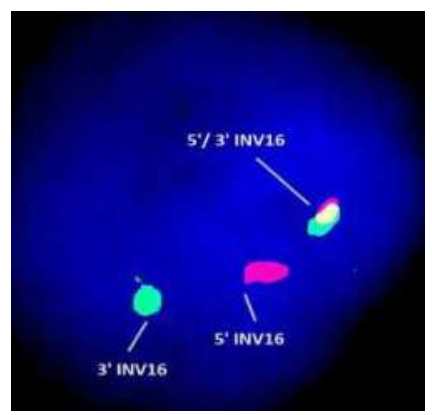

Fig. 10. Interphase FISH analysis showing 1red-1green-1yellow fusion signal pattern; as compared to the normal cells which show a pattern of 0red- 0green-2yellow (not shown). The splitting of yellow signal into 1red and 1green indicates translocation involving chromosome 16 in the region of CBFB (DAPI counterstain, $\times 1000$ ) 
detected by the formation of a red-green or yellow fusion signal. MLL gene is involved in more than 80 different translocations. To detect AL with MLL gene involvement break-apart probes complimentary to MLL gene are useful. This approach has an advantage that it detects all types of MLL gene translocations, independent of the partner gene (van der Burg et al, 1999). However, for detecting specific abnormality, dual color dual-fusion specific probes are used to detect the balanced translocations. In cases of AML with myelodysplasia associated changes, where numerical aberrations are more common CEPs are used to detect $+8,-5,-7$, etc.

\subsection{PML nuclear bodies immunofluorescence test}

An immunofluorescence based test is developed for rapid diagnosis of APL, using antibodies directed against the amino terminal portion of the human PML gene product, PG-M3 monoclonal antibody (Falini B et al, 1997). The wild type PML produces a characteristic nuclear speckled pattern that is due to localization of the protein into discrete dots (5 to 20 per nucleus), named PML nuclear bodies. The architecture of PML nuclear bodies appears to be disrupted in APL cells that bear the $t(15 ; 17)$, thus resulting in abnormal (micropunctate) pattern of the PML/RARA fusion protein (usually $\geq 50$ small granules/per nucleus). These are characteristically seen in APL with PML/RARA translocation and not in PLZF/RARA APL and other AMLs. Immunocytochemical labeling with PG-M3 represents a rapid, sensitive, and highly-specific test for the diagnosis of APL that bears the $t(15 ; 17)$ and allows an easy and correct diagnosis of this subtype of acute leukemia to any laboratory provided with a minimal equipment for immunocytochemistry work.

\subsection{Polymerase chain reaction}

Nucleic acid amplification studies have become an integral part of diagnostic and prognostic work-up in the field of hematology. These include detection of DNA or the RNA by a process known as polymerase chain reaction (PCR). A marrow or peripheral blood specimen is routinely taken for molecular diagnostics. Ideally, DNA and RNA should be extracted and viable cells stored; if sample quantity is limited, RNA extraction should be a priority, because RNA is suitable for molecular screening for fusion genes and leukemiaassociated mutations.

\subsubsection{PCR in the diagnosis of recurrent genetic abnormalities}

Molecular diagnosis by RT-PCR for the recurring gene fusions, such as RUNX1-RUNX1T1, CBFB-MYH11, MLLT3-MLL, DEK-NUP214, can be useful in certain circumstances. RT-PCR is an option to detect these rearrangements, if chromosome morphology is of poor quality, or if there is typical marrow morphology but the suspected cytogenetic abnormality is not present and for a rapid diagnosis (Mrózek K et al, 2001). The standardized protocols are published by the BIOMED-1 group (van Dongen JJM et al, 1999).

Acute Promyelocytic Leukemia with PML/RARA translocation: Five different chromosomal translocation partners have been identified in patients with APL, and all involve the RARA gene on chromosome 17q21 fused to one of the partners, PML on chromosome 15q22 being the most common. This results in fusion PML/RARA, mRNA transcription and a chimeric protein. RT- PCR amplification of the PML/RARA fusion transcript is now widely used for both diagnostic and monitoring studies (Sirulnik A et al, 2003). 


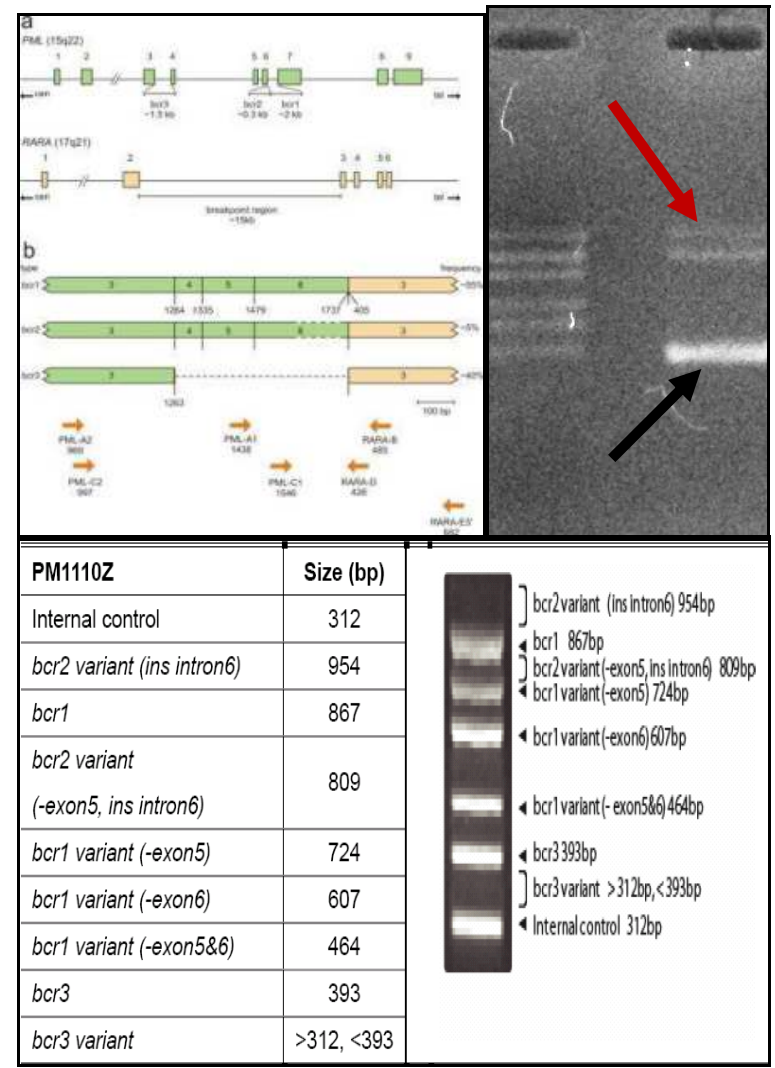

Fig. 11. The upper left panel shows a schematic representation of possible break-points in the PML and RARA genes, thus generating the isoforms - bcr1, bcr2 or bcr3 of PML-RARA fusion transcript. (Idea adapted from van Dongen JJM et al, 1998). The bcr1 and bcr2 breakpoint regions are juxtaposed in intron 6 and exon 6, respectively. The upper right panel shows presence of bcr1 form of PML-RARA transcript (red arrow) with an internal control (black arrow). The lower panel gives a reference chart for the location of various PML-RARA transcripts and their relative sizes based on the number of base pairs

The exact type of breakpoint on the PML gene can be determined. RT-PCR allows the detection of minimal residual disease at high sensitivity levels. Some pitfalls include poor RNA yield and stability, as well as the low expression of the hybrid PML/RARA gene. The chromosome 17 breakpoints are localized within a $15 \mathrm{~kb}$ DNA fragment of the RARA intron 2. The PML gene spans $35 \mathrm{~kb}$ of genomic DNA and contains nine exons (Chen $\mathrm{Z} \&$ Chen SJ, 1992; Sirulnik A et al, 2003). Three regions of the PML locus are involved in the translocation breakpoints: intron 6 (bcr1; 55\% of cases), exon 6 (bcr2; 5\%), and intron 3 (bcr3; 40\%). Bcr1 and bcr2 are considered as long (L) forms and bcr3 is considered as short (S) form (Figure 11). Because bcr2 (also referred to as 'variant' or V form) and bcr1 are located in PML exon 6 and intron 6, respectively, sequencing of all $\mathrm{L}$ transcript cases would be needed to clearly distinguish these two isoforms. There is no difference in the clinical features of various 
isoforms (Lo-Coco F et al, 1999, 2003; van Dongen JJM et al, 1999). Recognition of the infrequent PLZF/RARA subtype is clinically relevant in the light of its presumed unresponsiveness to ATRA and other agents such as arsenic trioxide (Lo-Coco F et al, 2003).

Acute myeloid leukemia with RUNX1-RUNX1T1 or AML-ETO: The $t(8 ; 21)$ fuses the RUNX1 or AML1 or CBFA2 gene on chromosome 21 to the RUNX1T1 or ETO gene on chromosome 8. RUNX1-RUNX1T1/ AML1-ETO fusion transcripts are found by RT-PCR in virtually all cases of $t(8 ; 21)$-positive AML, including those with complex translocations and also in a significant proportion of $t(8 ; 21)$-negative AML (van Dongen JJM et al, 1999). Transcripts of this fusion gene can be specifically and sensitively detected by RT-PCR. They generate predominant PCR products of a constant size, corresponding to an in-frame fusion of AML1 exon 5 to ETO exon 2 (Downing JR et al, 1993; Liu Yin JA, 2002).

Acute myeloid leukemia with CBFB-MYH11: This translocation involves fusion of CBFB gene located on16q22 with MYH11 gene located on 16p13. There is marked heterogeneity in the fusion transcripts, arising from variable genomic breakpoints in both CBFB and MYH11 genes and alternative splicing. Ten different CBFB-MYH11 fusion transcripts have been reported and have been designated as types A to J (Liu Yin JA, 2002; van Dongen JJM et al, 1999). More than $85 \%$ of the positive patients have type A transcript; two other transcripts (D and E) represent nearly 5\% each, whereas all others represent unique cases (Liu PP et al, 1995; Liu Yin JA, 2002).

Other cytogenetic abnormalities: There are primers directed to diagnose other recurring genetic abnormalities, especially those involving MLL gene, the partners being MLLT3 / AF9, AF6, AF10, ENL, etc. In addition PCR can be used to diagnose DEK-CAN related to $\mathrm{t}(6 ; 9)(\mathrm{q} 23 ; \mathrm{q} 34)$, EVI-1 associated with inv 3(q21;q26)/ $\mathrm{t}(3 ; 3)$ (q21;q26), AML1-EVI-1, $\mathrm{t}(3 ; 21)(\mathrm{q} 26 ; \mathrm{q} 22)$ and rarely the BCR-ABL1, i.e. $\mathrm{t}(9 ; 22)(\mathrm{q} 24 ; \mathrm{q} 11)$ (Swerdlow SH et al, 2008; Vardiman JW et al, 2009). Although BCR-ABL1-positive AML has been reported, criteria for its distinction from CML initially manifesting in a blast phase are not entirely convincing, and for this reason, BCR-ABL1-positive AML is not recognized in this classification. Many cases of BCR-ABL1- related AL will meet the criteria for ALL or MPAL, provided that a blast phase of a previously unrecognized CML can be excluded (Vardiman JW et al, 2009). GATA 1 mutations are detected in children less than 5 years in cases of AML associated with Down's syndrome. (Swerdlow SH et al, 2008; Xavier AC \& Taub JW, 2009)

\subsubsection{Cytogenetically Normal AML}

According to the various cytogenetic classifications mentioned above around $50 \%$ to $70 \%$ of AML patients are considered to be a part of an intermediate-risk group. Most of these patients have a normal karyotype (40-50\% of all AML patients), but the heterogeneity is most pronounced in this group (Schlenk RF et al, 2008). Somatically acquired mutations have been identified in several genes, the notable ones are the NPM 1, CEBPA, and FLT3, which have been proven to have prognostic implications. AML with mutations in NPM1 or CEBPA have been incorporated in the WHO classification as provisional entities. The FLT3 internal tandem duplication (ITD) mutation was detected and found to be the most common gene mutation in AML. Subsequent research shows that mutations of the NPM1 gene can occur in up to $60 \%$ of patients with AML and are most common in patients with a normal karyotype. The European Leukemia Net panel recommends that mutations of NPM1, CEBPA and FLT3 be analyzed at least in patients with CN-AML who will receive treatment other than low-dose chemotherapy or best supportive care (Döhner H et al, 2010; Döhner K 
\& Döhner H, 2008). There are few more as MLL, BAALC, WT1, etc which have also an impact on the prognosis.

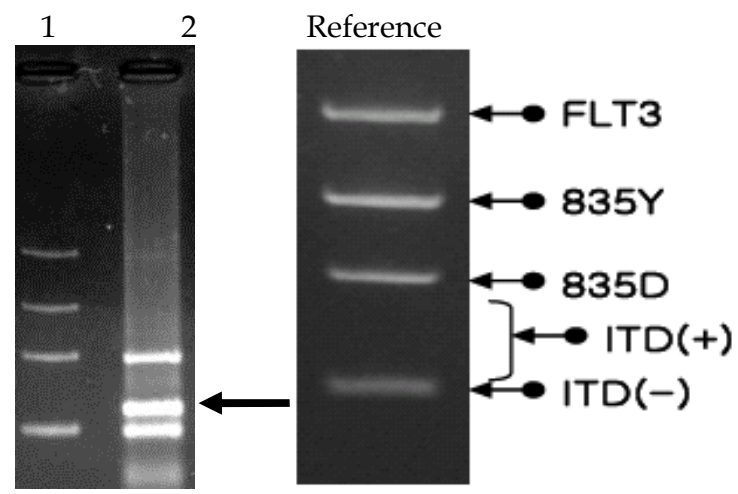

Fig. 12. A patient showing FLT3 - ITD in lane 2 (arrow) as a distinct band from the wild type of FLT-3. Lane 1 shows 100bp markers. The reference gel on the right panel shows the various locations of the wild and mutant products.

Mutations of the nucleophosmin, member 1 (NPM1) gene: Mutations of NPM1 gene, which codes for a nuclear/cytoplasmic shuttling protein, are found in 50-60\% of CN-AML cases (Schiffer CA, 2008). Heterozygous mutations in exon 12 of the NPM1 gene, results in abnormal cytoplasmic expression of its protein product, nucleophosmin. The presence of NPM1 mutations has been associated with pretreatment features as female sex, increased bone marrow blast percentages, LDH levels, WBC and platelet counts, and low or absent CD34 expression. In many studies, the presence of NPM1 mutation in CN-AML has been associated with good prognosis. $40 \%$ of patients with NPM1 mutations also harbor FLT3ITDs (Döhner K et al, 2005; Falini B et al, 2006; Schnittger $S$ et al, 2005; Thiede C et al, 2006).

Mutations of the CCAAT/enhancer-binding protein alpha (CEBPA) gene: CEBPA protein is critical for normal hematopoietic differentiation and loss of activity either by mutation or epigenetic silencing can result in a block in normal differentiation. The incidence varies between $7 \%$ and $20 \%$ in various studies (Schiffer CA, 2008). Those with CEBPA mutations present with higher percentages of peripheral blood blasts, lower platelet counts, less lymphadenopathy and extramedullary involvement, and are less likely to also carry FLT3ITD, FLT3-TKD and MLL-PTD. CEBPA mutations confer favorable prognosis. CEBPA mutations are best studied by DNA sequencing, and hence are not available on a routine basis.

FLT 3 mutations: FLT3 is a transmembrane tyrosine kinase receptor with important roles in hematopoietic stem/progenitor cell survival and proliferation. FLT3 is the most frequently mutated gene in AML. Different mutations of the gene exist. Most common are the internal tandem duplications (ITDs) in the juxta membrane domain (JMD) and found in 23\% of AML patients (Figure 12). FLT3-ITD can be detected in all subtypes of AML but contradictory results have been published concerning its relationship with FAB type (Bacher $U$ et al, 2008; Boissel N et al, 2006; Cairoli $\mathrm{R}$ et al, 2006; Frohling $\mathrm{S}$ et al, 2002; Gale RE et al, 2008; Kottaridis PD et al, 2001; Schnittger $S$ et al, 2002). Its incidence is associated with hyperleukocytosis and age (Cairoli $\mathrm{R}$ et al, 2006). The frequency is higher in elderly patients 
and lower in children. FLT3 is highly expressed in infant MLL gene re-arranged ALL and offers an interesting target for this high-risk group of patients (Döhner $\mathrm{H}$ et al, 2010). In addition to FTL3-ITD, point mutations in the FLT3 gene involving aspartic acid 835 of the kinase domain (KD), may also lead to constitutive activation of the receptor. FLT3-KD point mutations in other sites are found less frequently. FLT3-KD point mutations are seen in 8$12 \%$ of AML patients. Both types of mutation constitutively activate FLT3. Many studies in AML have shown that the presence of ITD mutations portends a poor prognosis. Thiede et al showed that the outcome of AML patients is dependent on the ratio of mutant and wildtype FLT3 (Thiede $\mathrm{C}$ et al, 2002). In most studies the KD point mutants do not seem to have the same unfavorable prognostic effect. FLT3 mutations can also be detected in other types of AML including those with t (6;9) and APL (Schiffer CA. 2008). Testing for FLT3 mutations in younger patients, i.e. less than 60 years of age, with de novo AML is now recommended by the NCCN Practice Guidelines in Oncology. Testing for FLT3-ITD and for the other molecular markers is available mostly at only the large university centers and is performed as part of clinical trials (NCCN, 2006).

Overexpression of WT1 (Wilm's Tumor 1) gene: The levels of WT1 were found to be $10^{2}-$ $10^{3}$ times higher in AML than in normal bone marrow, where it is either undetectable or expressed at very low levels. WT1 is over-expressed in approximately $90 \%$ of AML patients, except in FAB AML-M5, where its expression is lower (Gaidzik VI et al, 2009; Inoue K et al, 1994; King-Underwood L et al, 1996; Liu Yin JA, 2002; Paschka P et al, 2008). Many studies show that levels of WT1 transcript are prognostically valuable and can predict early relapse in AML.

\section{Miscellaneous}

Partial tandem duplication (PTD) of the MLL (mixed lineage leukemia) gene was the first molecular alteration shown to impact on clinical outcome of CN-AML patients. It is detected in approximately $5 \%$ to $10 \%$ of these patients. Patients with MLL-PTD have a poorer prognosis than patients without the MLL-PTD (Mrózek K, \& Bloomfield CD, 2006). Overexpression of the BAALC gene in $\mathrm{PB}$ at diagnosis was detected in adults under the age of 60 years. These are associated with lower WBC, less frequent diagnosis of FAB M5 AML and an unfavourable prognosis (Mrózek K, \& Bloomfield CD, 2006). ERG overexpression is a recently identified molecular marker predicting adverse outcome (Mrózek K, \& Bloomfield CD, 2006). Mutations of the C- KIT proto-oncogene, a tyrosine kinase receptor, result in a constitutive proliferative signal, have been described in patients with CBF- AML, with data suggesting a poorer outcome in patients with this additional mutation (Mrózek K, \& Bloomfield CD, 2006; Schiffer CA, 2008).

\subsection{Electron microscopy}

The role of electron microscopy has diminished ever since the introduction of flow cytometry in the diagnostic work-up. Currently the WHO recognizes its role in the diagnosis of acute basophilic leukemia, which is characterized by the presence of granules containing structures characteristic of basophil precursors. These structures are electron dense particulate substance, are internally bisected, or contain crystalline material arranged in pattern of scrolls or lamellae (Swerdlow SH et al, 2008). The demonstration of metachromatic granules with toluidine blue stain and flow cytometry are enough to make the diagnosis. 


\subsection{Role of clinical history}

The role of clinical evaluation cannot be undermined for any diagnosis and evaluation of etiology and other prognostic factors. However, in the diagnostic algorithm of AML, clinical history is a vital component. A past history of receiving chemotherapy or radiation is of paramount importance to categorize therapy related AML. Similarly past history of myelodysplasia is important for the diagnosis of AML with myelodysplasia related changes. In a known scenario of Down's syndrome AML should be separately grouped. Usually all these entities require cytogenetics supplementation.

\begin{tabular}{|c|c|c|}
\hline Factors & Good & Poor \\
\hline Clinical Parameters & $\begin{array}{l}\text { ECOG } \leq 1 \\
\text { No CNS or extramedullary } \\
\text { tumors }\end{array}$ & $\begin{array}{l}\text { Age }<2 \text { and }>60 \text { years } \\
\text { ECOG }>1 \\
\text { AML with prior } \\
\text { chemotherapy or MDS } \\
\text { CNS involvement } \\
\text { Extramedullary tumors }\end{array}$ \\
\hline $\begin{array}{l}\text { Laboratory } \\
\text { Parameters }\end{array}$ & TLC $<25000 /$ cu.mm & $\begin{array}{l}\text { TLC > 100,000/ cu.mm } \\
\text { Elevated LDH }\end{array}$ \\
\hline Morphology & FAB AML-M3, M2, M4Eo & FAB AML-M0, M6, M7 \\
\hline Immunophenotype & CD19, CD2 expression & CD56, CD7 expression \\
\hline Cytogenetics & $\begin{array}{l}\mathrm{t}(15 ; 17) ; \mathrm{t}(8 ; 21) \\
\operatorname{inv}(16) / \mathrm{t}(16 ; 16)\end{array}$ & $\begin{array}{l}\text { Complex karyotype } \\
\text { inv }(3) \text { or } t(3 ; 3), t(6 ; 9), t(6 ; 11) \text {, } \\
t(11 ; 19) \text {, monosomy } 5 \text {, or } 7\end{array}$ \\
\hline Molecular & $\begin{array}{l}\text { Presence of fusion } \\
\text { PML/RARA; RUNX1- } \\
\text { RUNX1T1; CBFB-MYH11; } \\
\text { Presence of NPM-1 mutation } \\
\text { without FLT3-ITD; CEBPA } \\
\text { mutations }\end{array}$ & $\begin{array}{l}\text { FLT3-Internal tandem } \\
\text { duplication; MLL-Partial } \\
\text { tandem duplication; BAALC, } \\
\text { WT-1, ERG-2 over- } \\
\text { expression; mutations of C- } \\
\text { KIT; }\end{array}$ \\
\hline Response to treatment & MRD negative & MRD positive \\
\hline
\end{tabular}

Table 4. Factors that influence prognosis

\section{Prognostic work-up}

There is a marked heterogeneity in the behavior of AML patients in terms of their response to the treatment and their survival rates. Various factors were found to have an effect on the prognosis in AML (Table 4) (Frohling S et al, 2006; Reinhardt D et al, 2000; Saxena A et al,1998). Several groups have published studies using cytogenetics to stratify patients into different risk groups (Byrd JC et al, 2002; Slovak ML et al, 2000). AML cytogenetic subgroups can be identified using molecular profiling with the potential for further subdividing patients to begin to explain the heterogeneity in outcome among patients of the same cytogenetic type. Cytogenetics and molecular studies are very important in the prognostication of acute leukemias. In cytogenetically favorable CBF-AML, the presence of a KIT mutation has been shown to have an unfavorable influence on outcome in retrospective studies (Boissel $\mathrm{N}$ et al, 2006; Cairoli $\mathrm{R}$ et al, 2006; Schnittger $\mathrm{S}$ et al, 2006). Numerous molecular markers are known to have impact on prognosis (Preudhomme C et al, 2002; 
Renneville A et al, 2009; Wouters BJ et al, 2009b). However, one needs to remember that it is the interaction of these factors, which are responsible for the ultimate prognosis, including the post-therapy remission status (Preisler H, 1993).

\section{Assessing the status of the therapeutic targets}

Ever since the introduction of all-trans retinoic acid and the Arsenic trioxide in the treatment of APL, imatinib in CML and rituximab in non-Hodgkin lymphomas of mature B-cell type, focus has been on developing specific drugs that would target those molecules and proteins that are specific to the leukemic cells and not affecting the normal hemopoietic cells. The various targets identified and worked upon in cases of AML are CD33, FLT3-ITD, enzymes as farnesyl transferase, histone deacetylase, P-glycoprotein, bcl-2 protein, and vascular endothelial growth factor (Stone RM, 2007). Of these the most widely are evaluated are CD33 and FLT3-ITD and its downstream pathway. Gemtuzumab ozogamicin (Mylotarg, CMA 676) is a monoclonal humanized anti-CD33 antibody chemically linked to the cytotoxic agent calicheamicin that inhibits DNA synthesis and induces apoptosis (Döhner $\mathrm{H}$ et al, 2010). It has shown significant activity in patients with relapsed acute myeloid leukemia, in elimination of minimal residual disease and in patients with APL who had evidence of disease only at the molecular level. Several FLT3selective tyrosine kinase inhibitors (e.g., midostaurin, lestaurtinib, sunitinib) have in vitro cytotoxicity to leukemia cells. A number of FLT3 inhibitors have reached clinical trials as monotherapy in relapsed or refractory AML patients, some or all of whom had FLT3 mutations (Döhner H et al, 2010; Small D, 2006). Keeping these facts in mind assessment of the potential targets should be undertaken before starting these drugs, best at the time of diagnosis.

\section{Evaluation of the baseline parameters useful during follow-up}

Post-treatment assessment of residual disease is an important prognostic marker. Conventional morphology, karyotyping and FISH have not proven to be of any practical utility. Currently the best parameters at the time of diagnosis which can be used as followup markers of disease are molecular transcripts and antigenic profile of the blasts. The practical guidelines are that: for patients with $t(15 ; 17), t(8 ; 21)$ and inv(16), which are about $30 \%$ of AML cases, it is recommended to quantify MRD by real-time RT-PCR (Liu Yin JA, 2002; Lo-Coco F et al, 1999, 2003). For patients without a molecular marker, the options are multiparameter flow-cytometry or assessment of the WT1, whichever is appropriate for a particular patient (Inoue K et al, 1994; Wood BL, 2007).

\section{Parameters to assess baseline general health and detect comorbidities}

The general health and comorbidities should be assessed at the time of diagnosis before the patient undertakes the treatment. These will be baseline results based on which the complications will be monitored during the treatment. The following tests should be performed - complete blood counts, biochemical analysis, coagulation tests (especially in APL), urine analysis, serum pregnancy test in women with child bearing potential, screening for Hepatitis A, B, C virus and HIV-1 and 2, chest radiograph and 12-lead EKG, ECHO cardiography and lumbar puncture, whenever indicated. 


\section{Planning for future}

Although not recommended on a routine basis, however, these tests should be planned in advance to avoid subsequent confounding results. If the patient is an ideal subject for allogeneic stem cell transplant, HLA typing and cross-matching of the patient and potential donors should be performed at the outset and the results be sent to the Bone marrow transplant registry. The patients' pretreatment leukemic marrow and blood should be stored within a biobank.

Genome-wide studies - The Probable Future: In recent years, DNA microarrays (complementary DNA (cDNA) and oligonucleotide), together with the availability of the complete nucleotide sequence of the human genome, have spurred the search for abnormalities in cancer, including AML (Wouters BJ et al, 2009a). There is enough data to support the fact that there is heterogeneity within established AML subtypes. The studies pertaining to the CBF-AMLs, each could be split into subgroups merely based on the GEP data (Wouters BJ et al, 2009a). Further validation of the generated data is necessary for assessing biologic significance.

\section{Approach in an ideal set-up}

The ideal work-up contains all elements described above with the aim of planning for future. The focus is to adopt whatever is clinically significant and proven in terms of diagnosis, prognosis, therapy, and disease monitoring at that point of time. It also involves archiving the necessary samples for future research and the data obtained thereafter may be available to incorporate newer information into clinical practice. The algorithms for this may be as illustrated in Figures 13, 14 \& 15.

\section{Approach in resource limited areas}

WHO 2008 is the most appropriate classification in terms of prognostication and pathogenesis. This is however, a resource intensive process and liable to deviations in large parts of the world. The constraints on men, machine and material required to adhere to the current WHO classification are very real. It becomes necessary to devise methods that simplify the steps of diagnosis, prognosis, and monitoring treatment response. We find in our experience that it is possible to provide meaningful laboratory support for our underresourced patient population. Morphology combined with cytochemistry forms the basis of identifying entities that are potentially curable [ALL, APL, AML with $t(8 ; 21)$ and AML with $\operatorname{inv}(16)]$ and those which are less likely to yield good response to treatment (AML-M0, AML with dyspoiesis, AML-NOS ). With this objective work-up is planned. If treatment is a definite choice, baseline markers for monitoring response are necessary. The lack of resources including finances, infrastructure, expertise and socio-cultural factors that hinder treatment options are considerable. In such a situation diagnosing acute leukemia and recognizing AML in itself is an important step in patient management. Hence, the approach needs to be tailored to individual patient. The work-up designed in these circumstances may not always be in accordance with WHO 2008 guidelines. However, the information derived from this classification has improved our approach. The important end-points in this approach are to distinguish AML from ALL, identify the good-prognostic categories among AML. The algorithm for the same is proposed here (Figure 16). 


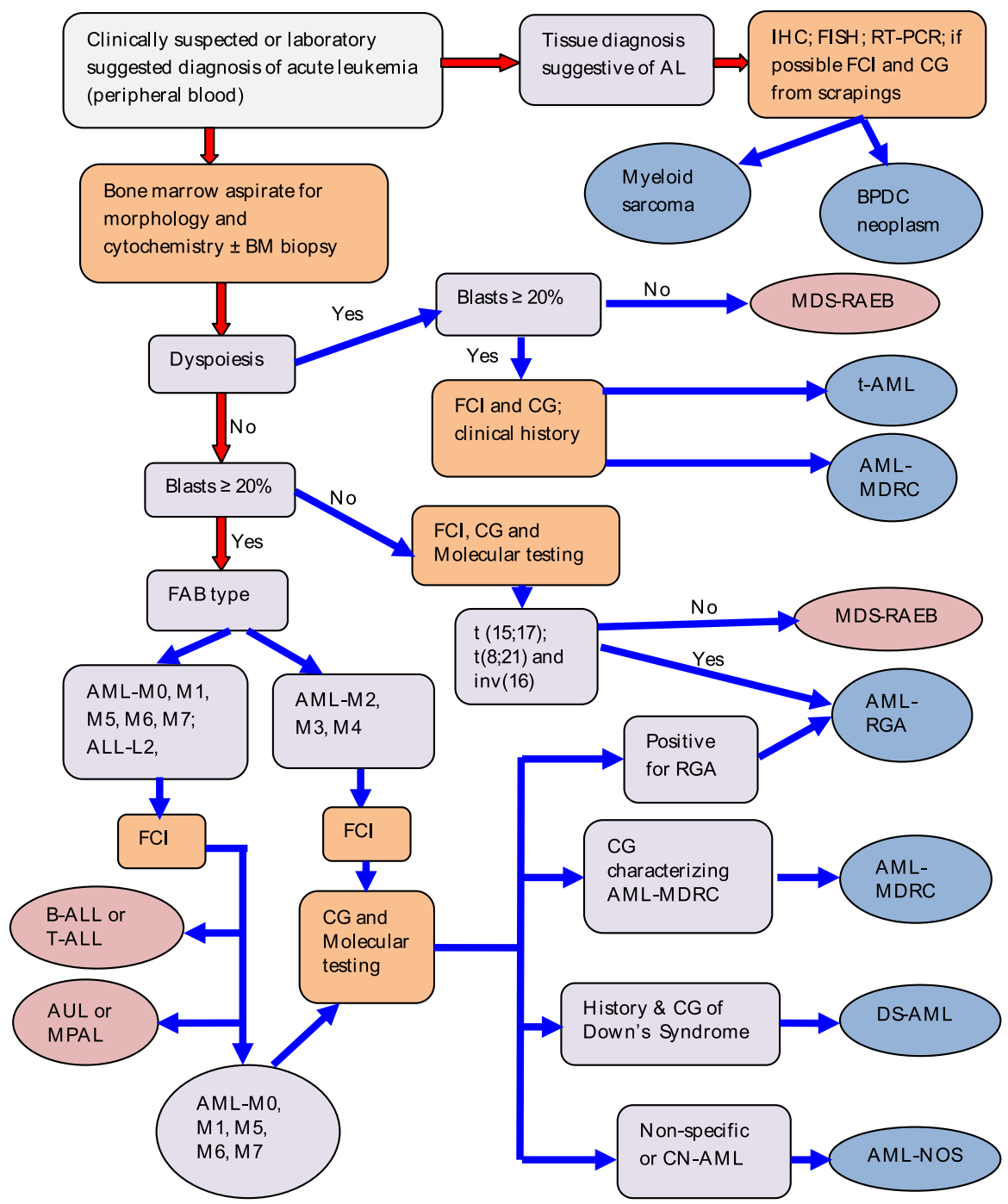

Abbreviations used (in alphabetical order) :AL-Acute leukemia; AML-Acute myeloid leukemia; AMLMDRC- AML with myelodysplasia related changes; ; AML-NOS- AML-Not otherwise Specified;AMLRGA- AML with recurrent cytogenetic abnormalities; AUL-Acute undifferentiated leukemia; B-ALL- BAcute Lymphoblastic Leukemia; BPDC-Blastic plasmacytoid dendritic cell; CG- Cytogenetics; CNAML-Cytogenetically normal AML; DS-AML- Down's Syndrome related AML; FAB-French-AmericanBritish; FCI-Flow cytometry Immunophenotyping; FISH-Fluorescent-in-situ hybridisation; IHCImmunohistochemistry;MDS-RAEB-Myelodysplastic syndrome-Refractory anemia with excess blasts; MPAL- Mixed Phenotypic acute leukemia; RT-PCR-Reverse Transcriptase Polymerase chain reaction; TALL- T-Acute Lymphoblastic Leukemia; t-AML-therapy related AML

Fig. 13. Algorithm for establishing the diagnosis of AML. The important testing points are highlighted in "Beige". The end-points related to AML are highlighted in blue and the differential diagnoses are highlighted in pink. 


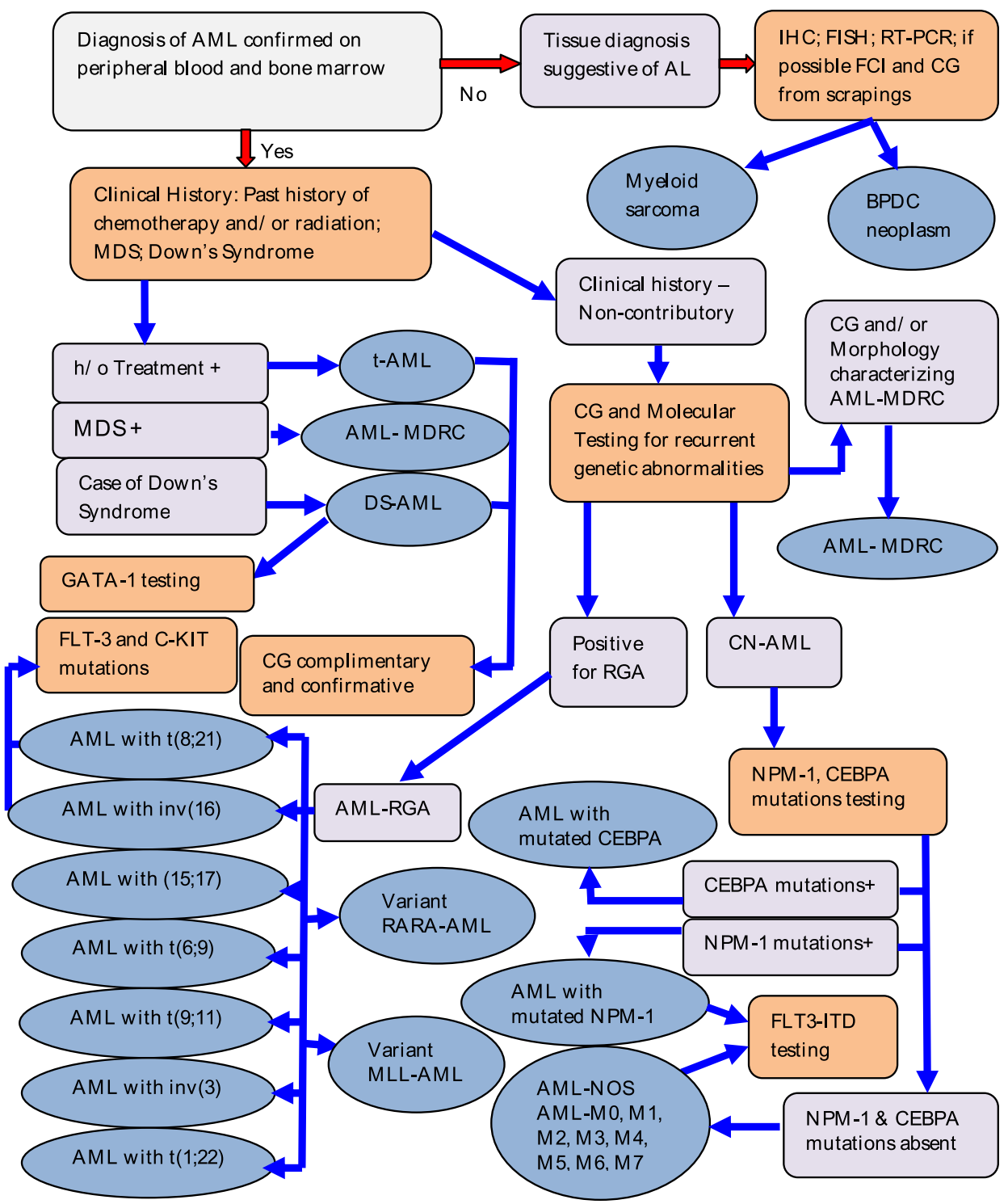

Abbreviations used (in alphabetical order) :AL-Acute leukemia; AML-Acute myeloid leukemia; AMLMDRC- AML with myelodysplasia related changes; AML-RGA- AML with recurrent cytogenetic abnormalities; BPDC-Blastic plasmacytoid dendritic cell; CG- Cytogenetics; CN-AML-Cytogenetically normal AML; DS-AML- Down's Syndrome related AML; FCI-Flow cytometry Immunophenotyping; FISH-Fluorescent-in-situ hybridisation; IHC-Immunohistochemistry; MDS-Myelodysplastic syndrome; RGA- Recurrent Genetic Abnormalities; RT-PCR-Reverse Transcriptase Polymerase chain reaction; tAML-therapy related AML

Fig. 14. Algorithm for Molecular Characterization of AML. The important testing points are highlighted in "Beige". The end-points related to AML are highlighted in blue. 


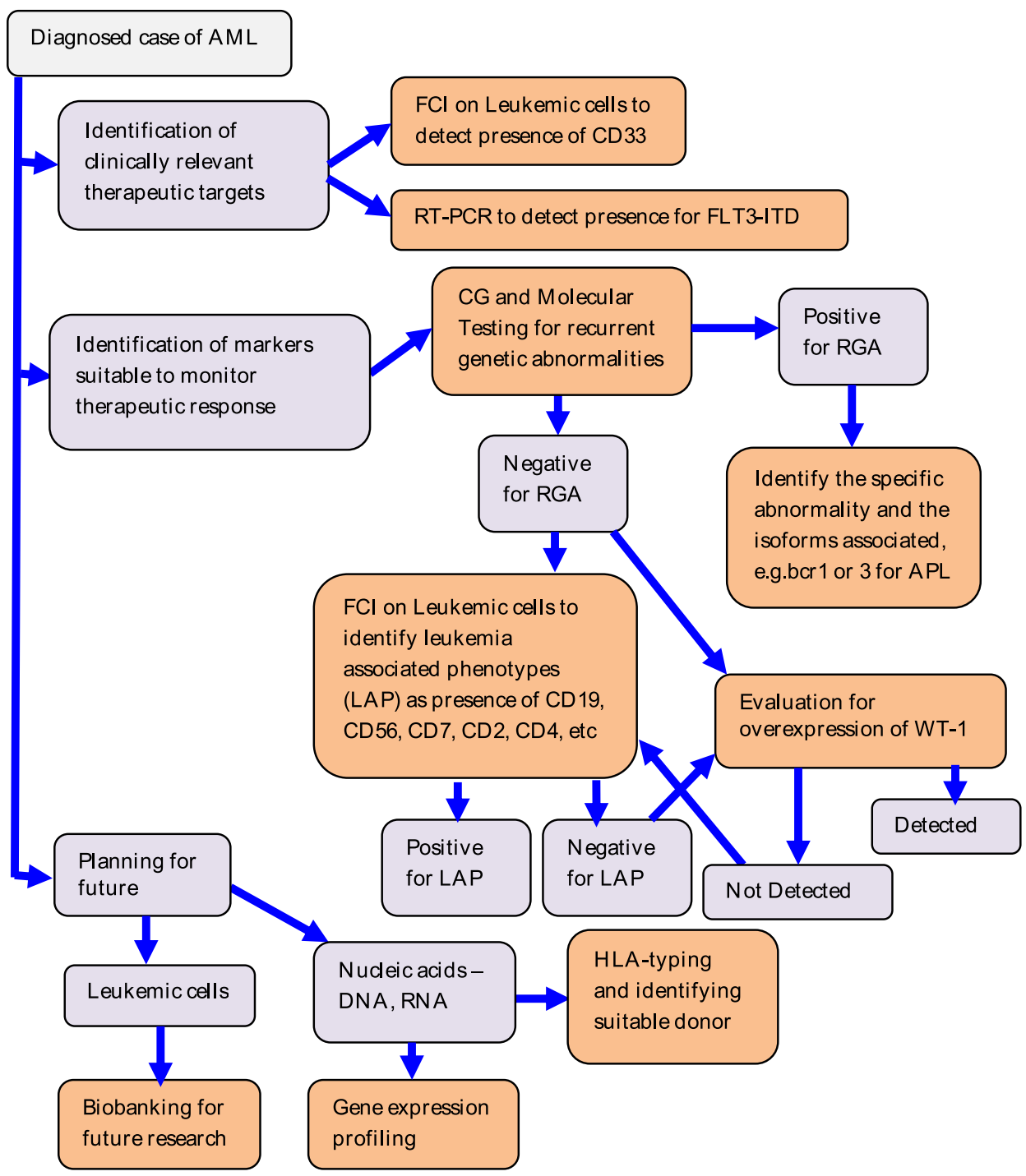

Abbreviations used (in alphabetical order) : AML-Acute myeloid leukemia; CG- Cytogenetics; FCI-Flow cytometry Immunophenotyping; RGA- Recurrent Genetic Abnormalities; RT-PCR-Reverse Transcriptase Polymerase chain reaction

Fig. 15. Algorithm for Identification of Therapeutic Targets, Markers for Disease Monitoring and Planning for future: The important interventions are highlighted in "Beige". 


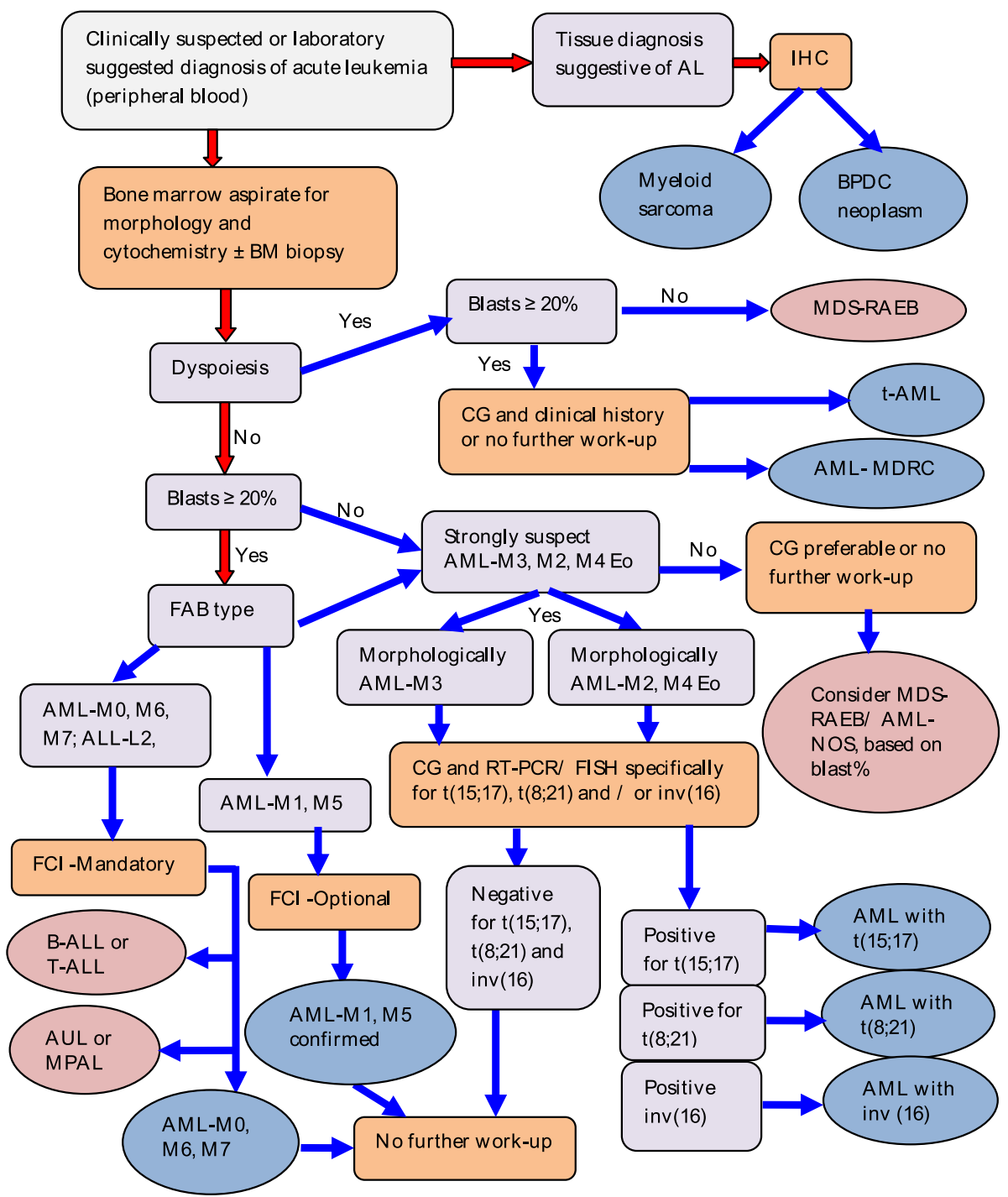

Abbreviations used (in alphabetical order) :AL-Acute leukemia; AML-Acute myeloid leukemia; AMLMDRC- AML with myelodysplasia related changes; AML-NOS- AML-Not otherwise Specified; AULAcute undifferentiated leukemia; B-ALL- B-Acute Lymphoblastic Leukemia; BPDC-Blastic plasmacytoid dendritic cell; CG- Cytogenetics; FAB-French-American-British; FCI-Flow cytometry Immunophenotyping; FISH-Fluorescent-in-situ hybridisation; IHC-Immunohistochemistry; MDSRAEB-Myelodysplastic syndrome-Refractory anemia with excess blasts; MPAL- Mixed Phenotypic acute leukemia; RT-PCR-Reverse Transcriptase Polymerase chain reaction; T-ALL- T-Acute Lymphoblastic Leukemia; t-AML-therapy related AML

Fig. 16. Diagnostic algorithm in resource constrained situations. The important testing points are highlighted in "Beige". The end-points related to AML are highlighted in blue and the differential diagnoses are highlighted in pink. 


\section{Acknowledgement}

We hereby are thankful to Dr. R.Tapadia for constant support and the staff of Lifeline Tapadia Diagnostic Services for the quality of technical work they deliver constantly. We also thank Ms.Archana for retrieving a lot of references. We thank Prof. KS Ratnakar, Global Hospital, Dr. KT Vijaya and Dr. Bhavana, Care Hospital, for facilitating photography. We profusely thank Dr.Salil, Gene Lab for the technical feedback for cytogenetics and other molecular testing and also for the images of cytogenetics, FISH and PCR. We are grateful to Dr.Reddy's laboratories, Hyderabad, India for sponsoring this chapter.

\section{References}

Adriaansen HJ, te Boekhorst PA, Hagemeijer AM, et al. (1993). Acute Myeloid Leukemia M4 With Bone Marrow Eosinophilia (M4Eo) and inv(16)(p13q22) Exhibits a Specific Immunophenotype with CD2 Expression. Blood, Vol. 81, No. 11, pp. (3043-3051)

Arber DA, Stein AS, Carter NH, et al. (2003). Prognostic impact of acute myeloid leukemia classification. Importance of detection of recurring cytogenetic abnormalities and multilineage dysplasia on survival. Am J Clin Pathol, Vol. 119, pp. (672-680)

Arber DA. (2010). Algorithmic approach to the classification of acute leukemia: United States \& Canadian Academy of Pathology (USCAP) Web site. http://www.uscap.org/site,/98th/pdf/companion21h02.pdf. Accessed June 4 2010

Auger M J, Ross JA, Ross FM, et al. (1992). CD7 Positive Acute Myeloblastic Leukaemia: An Heterogeneous Leukaemic Subtype. Leuk Lymphoma, Vol. 6, No. 6, pp. (487- 491)

Bacher U, Haferlach C, Kern W, et al. (2008). Prognostic relevance of FLT3-TKD mutations in AML: the combination matters-an analysis of 3082 patients. Blood, Vol. 111, No.5, pp. (2527-2536)

Baer MR, Stewart CC, Lawrence D, et al. (1997). Expression of the Neural Cell Adhesion Molecule CD56 Is Associated With Short Remission Duration and Survival in Acute Myeloid Leukemia With t(8; 21)(q22; q22). Blood, Vol. 90, No. 4, pp. (1643-1648)

Baer MR, Stewart CC, Lawrence D, et al. (1998). Acute myeloid leukemia with 11q23 translocations: myelomonocytic immunophenotype by multiparameter flow cytometry. Leukemia, Vol. 12, No. 3, pp. (317-325)

Bain BJ. (1998). Classification of acute leukaemia: the need to incorporate cytogenetic and molecular genetic information. J Clin Pathol, Vol. 51, pp. (420-423)

Bain BJ, Barnett D, Linch D, et al. (2002). Revised guideline on immunophenotyping in acute leukaemias and chronic lymphoproliferative disorders. Clin Lab Haematol, Vol. 24, No. 1, pp. (1-13)

Bain BJ. (2003). Leukaemia Diagnosis. (3rd edition) Blackwell Science, ISBN 1-4051-0661-1, Oxford.

Bene MC, Castoldi G, Knapp W, et al. (1995). Proposals for the immunological classification of acute leukemias. European Group for the Immunological Characterization of Leukemias (EGIL). Leukemia, Vol. 10, pp. (1783-1786)

Bennett JM, Catovsky D, Daniel M-T, et al. (1985). Criteria for the diagnosis of acute leukemia of megakaryocytic lineage (M7): a report of the French-American-British cooperative group. Ann Intern Med, Vol. 103, pp. (460-462) 
Bennett JM, Orazi A. (2009). Diagnostic criteria to distinguish hypocellular acute myeloid leukemia from hypocellular myelodysplastic syndromes and aplastic anemia: recommendations for a standardized approach. Haematologica, Vol. 94, pp. (264-268)

Betz BL, and Hess JL. (2010). Acute myeloid leukemia diagnosis in the 21st century. Arch Pathol Lab Med, Vol. 34, No. 10, pp. (1427-1433)

Boissel N, Leroy H, Brethon B, et al. (2006). Incidence and prognostic impact of c-Kit, FLT3, and Ras gene mutations in core binding factor acute myeloid leukemia (CBF-AML). Leukemia, Vol. 20, pp. (965-970)

Byrd JC, Mrózek K, Dodge RK, et al. (2002). Pretreatment cytogenetic abnormalities are predictive of induction success, cumulative incidence of relapse, and overall survival in adult patients with de novo acute myeloid leukemia: results from Cancer and Leukemia Group B (CALGB 8461). Blood, Vol. 100, pp. (4325-4336)

Cairoli R, Beghini A, Grillo G, et al. (2006). Prognostic impact of c-KIT mutations in core binding factor leukemias: an Italian retrospective study. Blood, Vol. 107, pp. (34633468)

Casasnovas RO, Campos L, Mugneret F, et al. (1998). Immunophenotypic patterns and cytogenetic anomalies in acute non-lymphoblastic leukemia subtypes: a prospective study of 432 patients. Leukemia, Vol. 12, pp. (34-43)

Chang CC, Eshoa C, Kampalath B, et al. (2000). Immunophenotypic profile of myeloid cells in granulocytic sarcoma by immunohistochemistry: correlation with blast differentiation in bone marrow. Am J Clin Pathol, Vol. 114, pp. (807-811)

Chen W, Rassidakis GZ, Li J, et al. (2006). High frequency of NPM1 gene mutations in acute myeloid leukemia with prominent nuclear invaginations ("cuplike" nuclei). Blood, Vol. 108, No. 5, pp. (1783-1784)

Chen Z and Chen SJ. (1992). RARA and PML Genes in Acute promyelocytic Leukemia. Leuk Lymphoma, Vol. 8, No. 4, pp. (253-260)

Chi Y, Lindgren V, Quigley S, et al. (2008). Acute Myelogenous Leukemia With $\mathrm{t}(6 ; 9)(\mathrm{p} 23 ; \mathrm{q} 34)$ and Marrow Basophilia-An Overview. Arch Pathol Lab Med, Vol. 132, pp. (1835-1837)

Chuang SS, Li CY. (1997). Useful panel of antibodies for the classification of acute leukemia by immunohistochemical methods in bone marrow trephine biopsy specimens. Am J Clin Pathol, Vol. 107, pp. (410-418)

Cohen PL, Hoyer JD, Kurtin PJ, et al. (1998). Acute myeloid leukemia with minimal differentiation: a multiple parameter study. Am J Clin Pathol, Vol. 109, pp. (32-38)

Corey SJ, Locker J, Oliveri DR, et al. (1994). A non-classical translocation involving 17q12 (retinoic acid receptor alpha) in acute promyelocytic leukemia (APML) with atypical features. Leukemia, Vol. 8, No. 8, pp. (1350-1353)

Craig FE and Foon KA. (2008). Flow cytometric immunophenotyping for hematologic neoplasms. Blood, Vol.111, No. 8, pp. (3941-3967)

Cuneo A, Ferrant A, Michaux JL, et al. (1995). Cytogenetic Profile of Minimally Differentiated (FAB MO) Acute Myeloid Leukemia: Correlation with Clinicobiologic Findings. Blood, Vol. 85, No. 12, pp. (3688-3694)

Döhner H, Estey EH, Amadori S, et al. (2010). Diagnosis and management of acute myeloid leukemia in adults: recommendations from an international expert panel, on behalf of the European LeukemiaNet. Blood, Vol. 115, pp. (453-474) 
Döhner K, Schlenk R F, Habdank M, et al. (2005). Mutant nucleophosmin (NPM1) predicts favorable prognosis in younger adults with acute myeloid leukemia and normal cytogenetics: interaction with other gene mutations. Blood, Vol. 106, pp. (3740-3746)

Döhner K and Döhner H. (2008). Molecular characterization of acute myeloid leukemia. Haematologica, Vol. 93, No. 7, pp. (976-982)

Downing JR, Head DR, Curcio-Brint AM, et al. (1993). An AML1/ETO fusion transcript is consistently detected by RNA-based polymerase chain reaction in acute myelogenous leukemia containing the $(8 ; 21)(\mathrm{q} 22 ; \mathrm{q} 22)$ translocation. Blood, Vol. 81 , No. 11, pp. (2860-2865)

Dunphy CH, Polski JM, Evans HL, et al. (2001). Evaluation of Bone Marrow Specimens With Acute Myelogenous Leukemia for CD34, CD15, CD117, and Myeloperoxidase. Arch Pathol Lab Med, Vol. 125, pp. (1063-1069)

Dunphy CH. (2004). Applications of Flow Cytometry and Immunohistochemistry to Diagnostic Hematopathology. Arch Pathol Lab Med, Vol. 128, pp. (1004-1022)

Dunphy CH, Tang W. (2007). The Value of CD64 Expression in Distinguishing Acute Myeloid Leukemia with Monocytic Differentiation From Other Subtypes of Acute Myeloid Leukemia A Flow Cytometric Analysis of 64 Cases. Arch Pathol Lab Med, Vol. 131, pp. (748-754)

Falini B, Flenghi L, Fagioli M, et al. (1997). Immunocytochemical Diagnosis of Acute Promyelocytic Leukemia (M3) With the Monoclonal Antibody PG-M3 (Anti-PML). Blood, Vol. 90, No. 10, pp. (4046-4053)

Falini B, Martelli M P, Bolli N, et al. (2006). Immunohistochemistry predicts nucleophosmin (NPM) mutations in acute myeloid leukemia. Blood, Vol.108, pp. (1999-2005)

Farag SS, Archer KJ, Mrozek K, et al. (2006). Pretreatment cytogenetics add to other prognostic factors predicting complete remission and long-term outcome in patients 60 years of age or older with acute myeloid leukemia: results from Cancer and Leukemia Group B 8461. Blood, Vol.108, pp. (63-73)

Frohling S, Schlenk R F, Breitruck J, et al. (2002). Prognostic significance of activating FLT3 mutations in younger adults (16 to 60 years) with acute myeloid leukemia and normal cytogenetics: a study of the AML Study Group Ulm. Blood, Vol.100, pp. (4372-4380)

Frohling S, Schlenk R F, Kayse S, et al. (2006). Cytogenetics and age are major determinants of outcome in intensively treated acute myeloid leukemia patients older than 60 years: results from AMLSG trial AMLHD98-B. Blood, Vol. 108, pp. (3280-3288)

Gaidzik VI, Schlenk RF, Moschny S, et al. (2009). Prognostic impact of WT1 mutations in cytogenetically normal acute myeloid leukemia: a study of the German-Austrian AML Study Group. Blood, Vol. 113, pp. (4505-4511)

Gale RE, Green C, Allen C, et al. (2008). The impact of FLT3 internal tandem duplication mutant level, number, size, and interaction with NPM1 mutations in a large cohort of young adult patients with acute myeloid leukemia. Blood, Vol. 111, pp. (27762784)

Goasguen JE, Bennett J, Cox C, et al. (1991). Prognostic implication and characterization of the blast cell population in the myelodysplastic syndrome. Leuk Res, Vol. 15, pp. (1159-1165) 
Golomb HM, Rowley J, Vardiman JW, et al. (1980). “Microgranular" acute promyelocytic leukemia: a distinct clinical, ultrastructural and cytogenetic entity. Blood, Vol. 55, pp. (253-259)

Goyal M, Dattatreya PS, Goud I, et al. (2010). Cryptic PML-RARV positive acute promyelocytic leukemia with unusual morphology and cytogenetics. Indian J Pathol Microbiol, Vol. 53, pp. (817-819)

Grimwade DF, Gorman P, Duprez E, et al. (1997). Characterization of cryptic rearrangements and variant translocations in acute promyelocytic leukemia. Blood, Vol. 90, pp. (4876-4885)

Grimwade D, Walker H, Oliver F, et al. (1998). The Importance of Diagnostic Cytogenetics on Outcome in AML: Analysis of 1,612 Patients Entered Into the MRC AML 10 Trial. Blood, Vol. 92, pp. (2322-2333)

Grimwade D, Biondi A, Mozziconacci M-J, et al. (2000). Characterization of acute promyelocytic leukemia cases lacking the classic $t(15 ; 17)$ : results of the European Working Party. Blood, Vol. 96, pp. (1297-1308)

Grimwade D, Walker H, Harrison G, et al. (2001). The predictive value of hierarchical cytogenetic classification in older adults with acute myeloid leukemia (AML): analysis of 1065 patients entered into the United Kingdom Medical Research Council AML11 trial. Blood, Vol. 98, pp. (1312-1320)

Gujral S, Subramanyam PG, Patkar N, et al. (2008). Report of proceedings of the national meeting on "Guidelines for Immunophenotyping of Hematolymphoid Neoplasms by Flow Cytometry". Indian J Pathol Microbiol, Vol. 51, No. 2, pp. (161-166)

Hrusak O, Porwit-MacDonald A. (2002). Antigen expression patterns reflecting genotype of acute leukemias. Leukemia, Vol. 16, No. 7, pp. (1233-1258)

Inoue K, Sugiyama H, Ogawa H, et al. (1994). WT1 as a new prognostic factor and a new marker for the detection of minimal residual disease in acute leukemia. Blood, Vol. 84, pp. (3071-3079)

Jacob MC, Chaperot L, Mossuz P, et al. (2003). CD4 (+) CD56 (+) lineage negative malignancies: a new entity developed from malignant early plasmacytoid dendritic cells. Haematologica, Vol. 88, pp. (941-955)

Jaffe ES, Harris NL, Stein H, Vardiman JW, eds. (2001). World Health Organization Classification of Tumours. Pathology and Genetics of Tumours of Haematopoietic and Lymphoid Tissues. (3rd edition), IARC, Lyon, France.

Johannson B, Mertens F, Mitelman F, et al. (1994). Secondary chromosomal abnormalities in acute leukemias. Leukemia, Vol. 8, pp. (953-962)

Khalidi HS, Medeiros LJ, Chang KL, et al. (1998). The immunophenotype of adult acute myeloid leukemia: high frequency of lymphoid antigen expression and comparison of immunophenotype, French-American-British classification, and karyotypic abnormalities. Am J Clin Pathol, Vol.109, No. 2, pp. (211-220)

King-Underwood L, Renshaw J and Jones KP. (1996). Mutations in the Wilms' Tumor Gene WT1 in Leukemias. Blood, Vol. 87, pp. (2171-2179)

Kita K, Nakase K, Miwa H, et al. (1992). Phenotypical Characteristics of Acute Myelocytic Leukemia Associated With the $\mathrm{t}(8 ; 21)$ (q22;q22) Chromosomal Abnormality Frequent Expression of Immature B-Cell Antigen CD19 Together With Stem Cell Antigen CD34. Blood, Vol. 80, pp. (470-477) 
Kottaridis PD, Gale RE, Frew ME, et al. (2001).The presence of a FLT3 internal tandem duplication in patients with acute myeloid leukemia (AML) adds important prognostic information to cytogenetic risk group and response to the first cycle of chemotherapy: analysis of 854 patients from the United Kingdom Medical Research CouncilAML10 and 12 trials. Blood, Vol. 98, pp. (1752-1759)

Kussick SJ, Wood BL. (2003). Using 4-Color Flow Cytometry to Identify Abnormal Myeloid Populations. Arch Pathol Lab Med, Vol. 127, pp. (1140-1147)

Kussick SJ, Stirewalt DL, Yi HS, et al. (2004). A distinctive nuclear morphology in acute myeloid leukemia is strongly associated with loss of HLA-DR expression and FLT3 internal tandem duplication. Leukemia, Vol. 18, No. 10, pp. (1591-1598)

Liso V, Bennett J. (2003). Morphological and cytochemical characteristics of leukaemic promyelocytes. Best Pract Res Clin Haematol, Vol. 16, No. 3, pp. (349-355)

Liu PP, Hajra A, Wijmenga C, et al. (1995). Molecular pathogenesis of the chromosome 16 inversion in the M4Eo subtype of acute myeloid leukemia. Blood, Vol. 85, pp. (22892302)

Liu Yin JA (2002). Minimal residual disease in acute myeloid Leukaemia. Best Pract Res Clin Haematol, Vol. 15, No. 12, pp. (119-135)

Lo-Coco F, Diverio D, Falini B, et al. (1999). Genetic diagnosis and molecular monitoring in the management of acute promyelocytic leukemia. Blood, Vol. 94, pp. (12-22)

Lo-Coco F, Breccia M, Diverio D, et al. (2003). The importance of molecular monitoring in acute promyelocytic leukaemia. Best Pract Res Clin Haematol, Vol. 16, No. 3, pp. (503-520)

Lorand-Metze I, Vassallo I, Aoki RY, et al. (1991). Acute Megakaryoblastic Leukemia: Importance of Bone Marrow Biopsy in Diagnosis. Leuk Lymphoma, Vol. 4, No. 1, pp. $(75-79)$

Lugthart S, Drunen EV, Norden YV, et al. (2008). High EVI1 levels predict adverse outcome in acute myeloid leukemia: prevalence of EVI1 overexpression and chromosome 3q26 abnormalities underestimated. Blood, Vol. 111, pp. (4329-4337)

Manaloor EJ, Neiman RS, Heilman DK, et al. (2000). Immunohistochemistry Can Be Used to Subtype Acute Myeloid Leukemia in Routinely Processed Bone Marrow Biopsy Specimens-Comparison With Flow Cytometry. Am J Clin Pathol, Vol. 113, pp. (814822)

Marcucci G, Mrózek K, Ruppert AS, et al. (2005).Prognostic Factors and Outcome of Core Binding Factor Acute Myeloid Leukemia Patients With $\mathrm{t}(8 ; 21)$ Differ From Those of Patients With inv(16): A Cancer and Leukemia Group B Study. J Clin Oncol, Vol. 23, pp. (5705-5717)

McCormick SR, McCormick MJ, Grutkoski PS, et al. (2010). FLT3 Mutations at Diagnosis and Relapse in Acute Myeloid Leukemia Cytogenetic and Pathologic Correlations, Including Cuplike Blast Morphology. Arch Pathol Lab Med, Vol. 134, pp. (1143-1151)

Melnick A, and Licht JD. (1999). Deconstructing a disease: RAR alpha, its fusion partners, and their roles in the pathogenesis of acute promyelocytic leukemia. Blood, Vol. 93, No. 10, pp. (3167-3215)

Miwa H, Mizutani M, Mahmud N, et al. (1998). Biphasic expression of CD4 in acute myelocytic leukemia (AML) cells: AML of monocyte origin and hematopoietic precursor cell origin. Leukemia, Vol. 12, pp. (44-51) 
Moorman AV, Hagemeijer A, Charrin C, et al. (1998).The translocations, t(11;19)(q23;p13.1) and $\mathrm{t}(11 ; 19)(\mathrm{q} 23 ; \mathrm{p} 13.3)$ : a cytogenetic and clinical profile of 53 patients. European 11q23 Workshop participants. Leukemia, Vol. 12, No. 5, pp. (805-810)

Mrózek K, Prior TW, Edwards C, et al. (2001). Comparison of Cytogenetic and Molecular Genetic Detection of $t(8 ; 21)$ and inv(16) in a Prospective Series of Adults With De Novo Acute Myeloid Leukemia: A Cancer and Leukemia Group B Study. J Clin Oncol, Vol. 19, pp. (2482-2492)

Mrózek K, and Bloomfield CD. (2006). Chromosome Aberrations, Gene Mutations and Expression Changes, and Prognosis in Adult Acute Myeloid Leukemia. Hematology Am Soc Hematol Educ Program, Vol. 2006, No. 1, pp. (169-177)

Mrozek K, Marcucci G, Paschka P, et al. (2007). Clinical relevance of mutations and gene expression changes in adult acute myeloid leukemia with normal cytogenetics: are we ready for a prognostically prioritized molecular classification? Blood, Vol. 109, pp. (431-448)

Mufti GJ, Bennett JM, Goasguen J, et al. (2008). Diagnosis and classification of myelodysplastic syndrome: International Working Group on Morphology of myelodysplastic syndrome (IWGM-MDS) consensus proposals for the definition and enumeration of myeloblasts and ring sideroblasts. Haematologica, Vol. 93, pp.(1712-1717)

National Comprehensive Cancer Network. Clinical Practice Guidelines in Oncologyv.1.2006: Acute Myeloid Leukemia.

http://www.nccn.org/professionals/physician_gls/PDF/aml.pdf. Accessed July 29,2006

Nguyen D, Diamond LW, Braylan RC, et al. (2003). Flow Cytometry in Hematopathology: A Visual Approach to Data Analysis and Interpretation. Humana Press, Totowa, New Jersey

Olsen RJ, Chang C, Herrick JL, et al. (2008). Acute Leukemia Immunohistochemistry - A Systematic Diagnostic Approach. Arch Pathol Lab Med, Vol. 132, pp. (462-475)

Orfao A, Chillon MC, Bortoluci AM, et al. (1999). The flow cytometric pattern of CD34, CD15 and CD13 expression in acute myeloblastic leukemia is highly characteristic of the presence of PML-RAR alpha gene rearrangements. Haematologica, Vol. 84, No. 5, pp. (405-412)

Orfao A, Ortuno F, de Santiago M, et al. (2004). Immunophenotyping of acute leukemias and myelodysplastic syndromes. Cytometry A, Vol. 58, No. 1, pp. (62-71)

Paietta E, Ferrando AA, Neuberg D, et al. (2005). Activating FLT3 mutations in CD117/KIT(+) T-cell acute lymphoblastic leukemias. Blood, Vol. 106, pp. (44144415)

Paschka P, Marcucci G, Ruppert AS, et al. (2008). Wilms' Tumor 1 Gene Mutations Independently Predict Poor Outcome in Adults With Cytogenetically Normal Acute Myeloid Leukemia: A Cancer and Leukemia Group B Study. J Clin Oncol, Vol. 26, pp. (4595-4602)

Peters JM, Ansari MQ. (2011). Multiparameter Flow Cytometry in the Diagnosis and Management of Acute Leukemia. Arch Pathol Lab Med, Vol. 135, pp. (44-54)

Petrella T, Dalac S, Maynadie M, et al. (1999). Groupe Francaise d'Etude des Lymphomes Cutane's (GFELC). CD4+, CD56+ cutaneous neoplasms: a distinct hematological entity? Am J Surg Pathol, Vol. 23, pp. (137-146) 
Pileri SA, Ascani S, Cox MC, et al (2007). Myeloid sarcoma: clinico-pathologic, phenotypic and cytogenetic analysis of 92 adult patients. Leukemia, Vol. 21, pp. (340-350)

Porwit-MacDonald A, Janossy G, Ivory K, et al. (1996). Leukemia-associated changes identified by quantitative flow cytometry. IV. CD34 overexpression in acute myelogenous leukemia M2 with $\mathrm{t}(8 ; 21)$. Blood, Vol. 87, No. 3, pp. (1162-1169)

Preisler H. (1993). Poor Prognosis Acute Myelogenous Leukemia. Leuk Lymphoma, Vol. 9, No. 4, pp. (273-283)

Preudhomme C, Sagot C, Boissel N, et al. (2002). Favorable prognostic significance of CEBPA mutations in patients with de novo acute myeloid leukemia: a study from the Acute Leukemia French Association (ALFA). Blood, Vol. 100, pp. (2717-2723)

Reinhardt D, Pekrun A, Lakomek M, et al. (2000). Primary myelosarcomas are associated with a high rate of relapse: report on 34 children from the acute myeloid leukaemia-Berlin-Frankfurt-Muenster studies. Br J Haematol, Vol. 110, pp. (863-866)

Renneville A, Boissel N, Gachard N, et al. (2009). The favorable impact of CEBPA mutations in patients with acute myeloid leukemia is only observed in the absence of associated cytogenetic abnormalities and FLT3 internal duplication. Blood, Vol. 113, pp. (5090-5093)

Rizzatti EG, Garcia AB, Portieres FL, et al. (2002). Expression of CD117 and CD11b in bone marrow can differentiate acute promyelocytic leukemia from recovering benign myeloid proliferation. Am J Clin Pathol, Vol. 118, pp. (31-37)

Rowe D, Cotterill SJ, Ross FM, et al. (2000). Cytogenetically cryptic AML1-ETO and CBFbeta-MYH11 gene rearrangements: incidence in 412 cases of acute myeloid leukaemia. Br J Haematol, Vol. 111, pp. (1051-1056)

Sainty D, Liso V, Cantu` -Rajnold Ai, et al. (2000). A new morphologic classification system for acute promyelocytic leukemia distinguishes cases with underlying PLZF/RARA gene rearrangements. Blood, Vol. 96, pp. (1287-1296)

Saxena A, Sheridan DP, Card RT, et al. (1998).Biologic and clinical significance of CD7 expression in acute myeloid leukemia. Am J Hematol, Vol. 58, No. 4, pp. (278-284)

Schiffer CA. (2008). Molecular characterization of AML: a significant advance or just another prognostic factor? Best Pract Res Clin Haematol, Vol. 21, No. 4, pp.(621-628)

Schlenk RF, Benner A, Krauter J, et al. (2004). Individual patient data-based meta-analysis of patients aged 16 to 60 years with core binding factor acute myeloid leukemia: a survey of the German Acute Myeloid Leukemia Intergroup. J Clin Oncol, Vol. 22, pp. (3741-3750)

Schlenk RF, Döhner K, Krauter J, et al. (2008). Mutations and Treatment Outcome in Cytogenetically Normal Acute Myeloid Leukemia. N Engl J Med, Vol. 358, pp. (1909-1918)

Schnittger S, Schoch C, Dugas M, et al. (2002). Analysis of FLT3 length mutations in 1003 patients with acute myeloid leukemia: correlation to cytogenetics, FAB subtype, and prognosis in the AMLCG study and usefulness as a marker for the detection of minimal residual disease. Blood, Vol. 100, pp. (59-66)

Schnittger S, Schoch C, Kern W, et al. (2005). Nucleophosmin gene mutations are predictors of favorable prognosis in acute myelogenous leukemia with a normal karyotype. Blood, Vol. 106, pp. (3733-3739) 
Schoch C, Haase D, Haferlach T, et al. (1996). Incidence and implication of additional chromosome aberrations in acute promyelocytic leukemias with $t(15 ; 17)(q 22 ; \mathrm{q} 21)$ : A report on 50 patients. Br J Hematol, Vol. 94, pp. (493-500)

Scott CS, Ottolander GJD, Swirsky D, et al. (1993). Recommended Procedures for the Classification of Acute Leukaemias. Leuk Lymphoma, Vol.11, No.1, pp. (37-50)

Secker-Walker LM, Moorman AV , Bain BJ, et al. (1998).Secondary acute leukemia and myelodysplastic syndrome with 11q23 abnormalities. Leukemia, Vol. 12, pp. (840844)

Sirulnik A, Melnick A, Zelent A, et al. (2003). Molecular pathogenesis of acute promyelocytic leukaemia and APL variants. Best Pract Res Clin Haematol, Vol. 16, No. 3, pp. (387408)

Slack JL, Arthur DC, Lawrence D, et al. (1997) Secondary cytogenetic changes in acute promyelocytic leukemia: Prognostic importance in patients treated with chemotherapy alone and association with intron 3 breakpoint of the PML gene: A Cancer and Leukemia Group B study. J Clin Oncol, Vol. 15, pp.(1786-1795)

Slovak ML, Kopecky KJ, Cassileth PA, et al. (2000). Karyotypic analysis predicts outcome of preremission and postremission therapy in adult acute myeloid leukemia: a Southwest Oncology Group/Eastern Cooperative Oncology Group Study. Blood, Vol. 96, pp. (4075-4083)

Slovak ML, Gundacker H, Bloomfield CD, et al. (2006). A retrospective study of 69 patients with $t(6 ; 9)(p 23 ; q 34)$ AML emphasizes the need for a prospective, multicenter initiative for rare poor prognosis' myeloid malignancies. Leukemia, Vol. 20, pp. (1295-97)

Small D. (2006). FLT3 mutations: biology and treatment. Hematology Am Soc Hematol Educ Program, Vol. 2006, No.1, pp. (178-184)

Sorensen PHB, Chen C, Smith FO, et al. (1994). Molecular Rearrangements of the MLL Gene Are Present in Most Cases of Infant Acute Myeloid Leukemia and Are Strongly Correlated with Monocytic or Myelomonocytic, Phenotypes. J Clin Invest, Vol. 93, pp. (429-437)

Stone RM. (2007). Targeted agents in AML: much more to do. Best Pract Res Clin Haematol, Vol. 20, No. 1, pp. (39-48)

Swansbury GJ, Slater R, Bain BJ, et al. (1998). Hematological malignancies with $\mathrm{t}(9 ; 11)(\mathrm{p} 21$ 22;q23): a laboratory and clinical study of 125 cases - European 11q23 Workshop participants. Leukemia, Vol. 12, pp. (792-800)

Swerdlow SH, Campo E, Harris NL, et al. (2008). WHO Classification of Tumours of Haematopoietic and Lymphoid Tissues (ed 4th), IARC, Lyon, France.

Thiede C, Steudel C, Mohr B, et al. (2002). Analysis of FLT3-activating mutations in 979 patients with acute myelogenous leukemia: association with FAB subtypes and identification of subgroups with poor prognosis. Blood, Vol. 99, pp. (4326-4335)

Thiede C, Koch S, Creutzig E, et al. (2006).Prevalence and prognostic impact of NPM1 mutations in 1485 adult patients with acute myeloid leukemia (AML). Blood, Vol. 107, pp. (4011-4020)

van der Burg, Beverloo HB, Langerak AW, et al. (1999). Rapid and sensitive detection of all types of MLL gene translocations with a single FISH probe set. Leukemia, Vol. 13, pp. (2107-2113) 
van Dongen JJM, Macintyre EA, Gabert JA, et al. (1999). Standardized RT-PCR analysis of fusion gene transcripts from chromosome aberrations in acute leukemia for detection of minimal residual disease. Report of the BIOMED-1 Concerted Action: investigation of minimal residual disease in acute leukemia. Leukemia, Vol. 13, No.12, pp. (1901- 1928)

Vardiman JW, Harris NL, and Brunning RD. (2002).TheWorld Health Organization (WHO) classification of the myeloid neoplasms. Blood, Vol. 100, pp. (2292-2302)

Vardiman JW, Thiele J, Arber DA, et al. (2009).The 2008 revision of the World Health Organization (WHO) classification of myeloid neoplasms and acute leukemia: rationale and important changes. Blood, Vol. 114, pp. (937-951)

Weinberg OK, Seetharam M, Ren L, et al. (2009).Clinical characterization of acute myeloid leukemia with myelodysplasia-related changes as defined by the 2008 WHO classification system. Blood, Vol. 113, No. 9, pp. (1906-1908)

Weir EG, Borowitz MJ. (2001). Flow cytometry in the diagnosis of acute leukemia. Semin Hematol, Vol. 38, No.2, pp. (124-138)

Wells DA, Benesch M, Loken MR, et al. (2003). Myeloid and monocytic dyspoiesis as determined by flow cytometric scoring in myelodysplastic syndrome correlates with the IPSS and with outcome after hematopoietic stem cell transplantation. Blood, Vol. 102, No.1, pp. (394-403)

Wood BL. (2006). 9-Color and 10-Color Flow Cytometry in the Clinical Laboratory. Arch Pathol Lab Med, Vol. 130, pp. (680-690)

Wood BL. (2007). Myeloid Malignancies: Myelodysplastic Syndromes, Myeloproliferative Disorders, and Acute Myeloid Leukemia. Clin Lab Med, Vol. 27, pp. (551-575)

Wouters BJ, Lowenberg B and Delwel R. (2009a). A decade of genome-wide gene expression profiling in acute myeloid leukemia: flashback and prospects. Blood, Vol. 113, pp. (291-298)

Wouters BJ, Lowenberg B, Erpelinck-Verschueren CAJ, et al. (2009b). Double CEBPA mutations, but not single CEBPA mutations, define a subgroup of acute myeloid leukemia with a distinctive gene expression profile that is uniquely associated with a favorable outcome. Blood, Vol. 113, pp. (3088-3091)

Xavier AC and Taub JW. (2009).Down Syndrome and Malignancies: A Unique Clinical Relationship. J Mol Diagn, Vol. 11, No. 5, pp. (371-380)

Yanada M, Suzuki M, Kawashima K, et al. (2005). Long term outcomes for unselected patients with acute myeloid leukemia categorized according to the World Health Organization classification: a single center experience. Eur J Haematol, Vol. 74, pp. (418-423) 


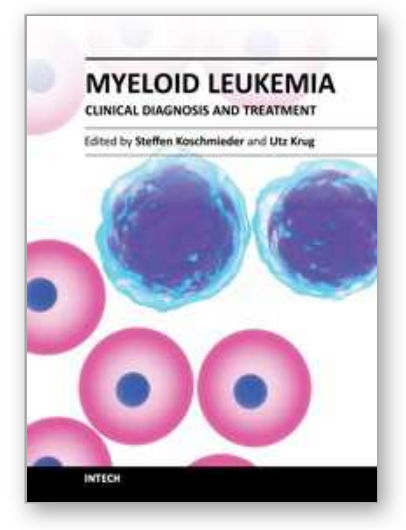

\author{
Myeloid Leukemia - Clinical Diagnosis and Treatment \\ Edited by Dr Steffen Koschmieder
}

ISBN 978-953-307-886-1

Hard cover, 296 pages

Publisher InTech

Published online 05, January, 2012

Published in print edition January, 2012

This book comprises a series of chapters from experts in the field of diagnosis and treatment of myeloid leukemias from all over the world, including America, Europe, Africa and Asia. It contains both reviews on clinical aspects of acute (AML) and chronic myeloid leukemias $(C M L)$ and original publications covering specific clinical aspects of these important diseases. Covering the specifics of myeloid leukemia epidemiology, diagnosis, risk stratification and management by authors from different parts of the world, this book will be of interest to experienced hematologists as well as physicians in training and students from all around the globe.

\title{
How to reference
}

In order to correctly reference this scholarly work, feel free to copy and paste the following:

Manu Goyal and K. Gayathri (2012). Diagnostic Approach in Acute Myeloid Leukemias in Line with WHO 2008 Classification, Myeloid Leukemia - Clinical Diagnosis and Treatment, Dr Steffen Koschmieder (Ed.), ISBN: 978953-307-886-1, InTech, Available from: http://www.intechopen.com/books/myeloid-leukemia-clinical-diagnosisand-treatment/diagnostic-approach-in-acute-myeloid-leukemias-in-line-with-who-2008-classification

\section{INTECH}

open science | open minds

\section{InTech Europe}

University Campus STeP Ri

Slavka Krautzeka 83/A

51000 Rijeka, Croatia

Phone: +385 (51) 770447

Fax: +385 (51) 686166

www.intechopen.com

\section{InTech China}

Unit 405, Office Block, Hotel Equatorial Shanghai

No.65, Yan An Road (West), Shanghai, 200040, China

中国上海市延安西路 65 号上海国际贵都大饭店办公楼 405 单元

Phone: +86-21-62489820

Fax: +86-21-62489821 
(C) 2012 The Author(s). Licensee IntechOpen. This is an open access article distributed under the terms of the Creative Commons Attribution 3.0 License, which permits unrestricted use, distribution, and reproduction in any medium, provided the original work is properly cited. 